\title{
FROM ELECTRON TO BIOMASS: A MECHANISTIC MODEL TO DESCRIBE PHYTOPLANKTON PHOTOSYNTHESIS AND STEADY-STATE GROWTH RATES ${ }^{1}$
}

\author{
Bernd M. A. Kroon \\ Im Steinviertel 6, D-27607 Langen, Germany \\ and \\ Silke Thoms ${ }^{2}$ \\ Alfred Wegener Institute for Polar and Marine Research, PO Box 1201 61, D-27515 Bremerhaven, Germany
}

A system of differential equations was presented which describes the rate of linear and cyclic electron flow through photosystems II and I. The system describes the rate of photochemistry in terms of electrons generated that are available for cellular metabolism, and results in a realistic description of photosynthesis as a function of irradiance without implicit assumptions for the relationship. The system allows a concise and detailed simulation of fluorescence kinetics. The derivation of the general degree of reduction $\left(\gamma_{x}\right)$ and its application to translate the rates of photochemistry (or measured fluorescence yields) to steady-state rates of carbon fixation and growth was shown. The efficiency of light-limited photosynthesis $(\alpha)$ was shown to depend on the cellular ratio of carbon to nitrogen. For any given antenna size, $\alpha$ increases with nitrate as $\mathrm{N}$-source, and decreases with ammonium as $\mathrm{N}$-source, if the cellular carbon to nitrogen ratio of the phytoplankton increases. Cyclic electron transport around photosystem $I$ increases the ratio of ATP generated relative to linear electron $\left(e^{-}\right)$flow. The increase of $\mathrm{ATP} / \mathrm{e}^{-}$is larger under extreme light-limiting conditions. The long-known fact that protein synthesis saturates at lower light intensities than carbonate synthesis was explained in terms of the decrease of $\mathrm{ATP} / \mathrm{e}^{-}$with increasing irradiance and the higher ATP demand of protein synthesis.

Key index words: carbon fixation; degree of reduction; electron transport model; fluorescence; photosynthesis; phytoplankton growth

Abbreviations: Fd, ferredoxin; FNiR, Fd-nitrite oxidoreductase; FNR, Fd-NADP ${ }^{+}$oxidoreductase; FRR, fast repetition rate; FTR, Fd-thioredoxin oxidoreductase; GOGAT, glutamine-oxoglutarate aminotransferase; ODEs, ordinary differential equations; PC, plastocyanin; PFD, photon flux density; PQ, plastoquinone

\footnotetext{
${ }^{1}$ Received 22 November 2004. Accepted 22 February 2006.

${ }^{2}$ Author for correspondence: e-mail sthoms@awi-bremerhaven.de.
}

The importance of phototrophic microorganisms and especially oceanic phytoplankton for life on earth was never challenged. Most research on photosynthesis, however, was driven by the need to investigate photosynthetic growth, in order to optimize yields and production rates of agricultural crops. While basic research successfully unravelled structural and functional features of the photosynthetic machinery, applied measurements focussed on the quantification of the most prominent signals of photosynthesis (oxygen evolution or carbon fixation) relative to irradiance. Many theories and models were developed to describe these so-called photosynthesis-irradiance $(\mathrm{P} / \mathrm{E})$ curves (Bannister 1979, Gallegos and Platt 1981) and these models were helpful to derive ecologically relevant photosynthetic production rates. Fewer models were developed that describe algal activity based on the biochemistry of macromolecular compounds (Shuter 1979, Geider and Platt 1986, Flynn et al. 1997, 2001, Flynn and Hipkin 1999, Flynn 2003). The increased awareness over the last decades that phytoplankton significantly contributes to global biogeochemical cycles has further stimulated the development of in situ measurement techniques and/or satellite platforms to monitor the amount and activity of phytoplankton (Behrenfeld et al. 2005). These new technologies acquire accurate data on large time and spatial scales. Logically, the technologies converge on detecting optical signals, because they contain information on both the amount of pigments as well as the photosynthetic activity of these pigments. The photosynthetic models now place more emphasis on light absorption and quantum yields (Kiefer and Mitchell 1983, Falkowski et al. 1985, Langdon 1987, Kroon et al. 1989), but still remain rooted in concepts of P/E curves (Dubinsky et al. 1986, Sakshaug et al. 1991, Baumert 1996).

Over the last decade, the fluorescence of photosynthetic pigments (Govindjee 1995) and its tight linkage to photochemistry led to the development of highly sophisticated fluorometers (Schreiber et al. 1986, Trtilek et al. 1997, Kolber et al. 1998), which allow a fast and non-intrusive measurement of photosynthetic activity. This led to the development of mechanistic models that quite accurately describe fluorescence 
phenomena (Trissl and Lavergne 1994, Stirbet et al. 1998, Lebedeva et al. 2002).

Overall, the different classes of recent photosynthetic models either emphasize $\mathrm{P} / \mathrm{E}$ relationships or metabolic fluxes, and are less suited to derive information from modern observation platforms, or they highlight biophysical fluorescence characteristics and are less suited to derive overall growth rates.

We propose a generalized model of phytoplankton steady-state growth, integrating the main mechanisms and processes in photosynthetic electron flow. It includes all intermediary steps from photon absorption and charge separation at PSII up to the reduction of the terminal electron carrier ferredoxin $(\mathrm{Fd})$ at the end of the electron transport chain. In particular, the model includes the representation of a free $P Q$ pool interacting with a $Q_{B}$ binding site at PSII, the cytochrome b6/f (cyt b6/f) complex, the Q-cycle, the binding of Fd to the cyt $\mathrm{b} 6 / \mathrm{f}$ (which allows for cyclic electron transport) and the electron transfer steps within PSI. Rates of proton transfer across the thylakoid membrane and ATP synthesis are easily derived. The pool-sizes of the electron carriers as well as the composition and size of the light harvesting system can be chosen at will. The model represents a system of ordinary differential equations which numerically describe the redox states of all carriers as well as time dependent fluorescence transients. Separate aspects of the model have been discussed elsewhere (Trissl and Lavergne 1994, Lebedeva et al. 2002). The function of the model is to investigate the roles of the individual structural elements of the photosynthetic electron transport chain and of the electron flow with respect to various observable photosynthetic quantities (e.g. P/E curve, growth rates) and fluorescence.

The differential equations describe photosynthesis in terms of electron flow, its most elementary product. The introduction of a parameter is needed to convert electron flow into steady-state rates of growth or carbon fixation. Based on the principle of the conservation of elements, we derive such a conversion parameter, the general degree of reduction for biomass, $\gamma_{x}$ (Roels 1983). The parameter $\gamma_{x}$ has an important physical meaning for photoautotrophs: $\gamma_{x}$ represents the number of electrons that are needed to synthesize one mole of $\mathrm{C}$ biomass (i.e. the amount of biomass that contains one mole of carbon). It is shown that $\gamma_{x}$ closes the gap between the fluorescence based parameters and the need to express photosynthesis in terms of primary production and steady-state growth. As a result of the photochemical nature of the model on the one hand, and the translation to rates of carbon fixation on the other hand, consequences of cyclic electron transport and cellular carbon to nitrogen ratios on well-known growth characteristics are shown.

\section{DERIVATION OF THE GENERAL DEGREE OF REDUCTION}

A growing organism exchanges compounds with its environment (Fig. 1). Five flows of compounds are considered here

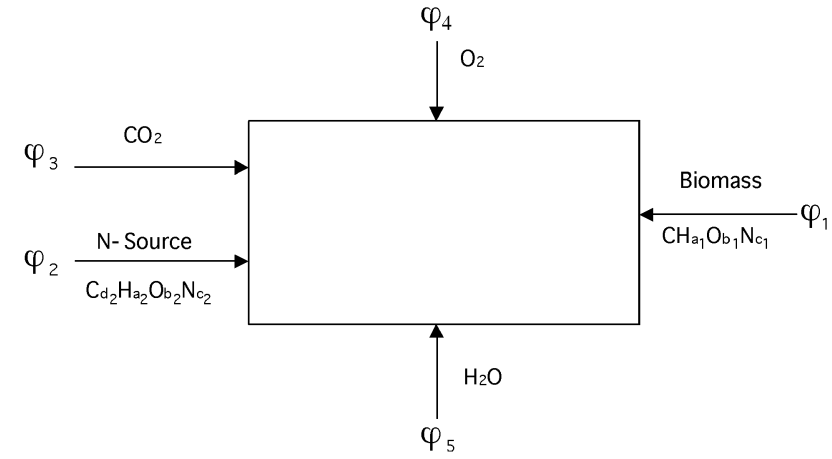

FIG. 1. Representation of a metabolizing photoautotrophic organism exchanging compounds (biomass, carbon dioxide, $\mathrm{N}$-source, oxygen, and water) expressed as flows $\varphi_{1}-\varphi_{5}$ with the environment. For the atomic composition, only the elements $\mathrm{C}, \mathrm{H}, \mathrm{O}$, and $\mathrm{N}$ are considered here. The elemental compositions for biomass and nitrogen source, which are used in the text, are indicated in the figure.

for the growth of photoautotrophic organisms: biomass, nitrogen source, carbon dioxide, oxygen and water, depicted as $\varphi_{1}$, $\varphi_{2}, \varphi_{3}, \varphi_{4}$, and $\varphi_{5}$, respectively. We neglect excretion of dissolved organic carbon and assimilated nitrogen, although these could be treated as other carbon- and nitrogen-specific flows. For such a system, the rate of change of each compound equals the sum of the rate of production (or consumption) of that compound plus the rate of transport of that compound to (or from) the system. From this so-called balance equation of the compounds, one can also derive a balance equation for the elements that are contained in the compounds. There is no limit to the number of elements that can be taken into account, but we will consider four elements (C, H, O, and N) here. The choice is based on the fact, that these elements make up $95 \%$ of the mass of phytoplankton and because available data on elemental composition include these elements. The elemental composition of the biomass equals $\mathrm{CH}_{\mathrm{a}_{1}} \mathrm{O}_{\mathrm{b}_{1}} \mathrm{~N}_{\mathrm{c}_{1}}$ and that of a given nitrogen source $\mathrm{C}_{\mathrm{d}_{2}} \mathrm{H}_{\mathrm{a}_{2}} \mathrm{O}_{\mathrm{b}_{2}} \mathrm{~N}_{\mathrm{c}_{2}}$. Because elements are conserved quantities in the biochemical reactions of an organism, the rate of change of each element equals 0 .

Applied to a system of a photoautotrophic organism, as depicted in Fig. 1, the following equations are valid in stationary state:

$$
\begin{array}{lc}
\text { For carbon } & \varphi_{1}+\mathrm{d}_{2} \varphi_{2}+\varphi_{3}=0 \\
\text { For hydrogen } & \mathrm{a}_{1} \varphi_{1}+\mathrm{a}_{2} \varphi_{2}+2 \varphi_{5}=0 \\
\text { For oxygen } & \mathrm{b}_{1} \varphi_{1}+\mathrm{b}_{2} \varphi_{2}+2 \varphi_{3}+2 \varphi_{4}+\varphi_{5}=0 \\
\text { For nitrogen } & \mathrm{c}_{1} \varphi_{1}+\mathrm{c}_{2} \varphi_{2}=0
\end{array}
$$

We now have a system of four linear equations describing five flows. Hence, if one (arbitrarily chosen) flow is known, the system can be solved for the other four flows. Let us assume that we know $\varphi_{4}$, the flow of oxygen. The solution for the flow for biomass then becomes:

$$
\varphi_{1}=4 \frac{\varphi_{4}}{\gamma_{x}}
$$

where

$$
\gamma_{x}=4+\mathrm{a}_{1}-2 \mathrm{~b}_{1}-\frac{\mathrm{c}_{1}\left(4 \mathrm{~d}_{2}+\mathrm{a}_{2}-2 \mathrm{~b}_{2}\right)}{\mathrm{c}_{2}}
$$

The symbol $\gamma_{x}$, as introduced in equation (5) and given by equation (6), represents the general degree of reduction of biomass. An extensive overview on $\gamma_{x}$ and its application on the 
energetics of (non-phototrophic) microbial growth is given by Roels (1983). In the special case of photoautotrophic organisms, $\gamma_{x}$ has a particular meaning: its value is equal to the number of moles of electrons required to synthesize one mole of $\mathrm{C}$ biomass from carbon dioxide and a nitrogen source. Thus, $\gamma_{x}$ offers a tool to convert the rate of photosynthetic electron production into other flows of compounds (notably carbon dioxide, oxygen and cellular biomass).

If the elemental compositions of biomass and nitrogen source are known, $\gamma_{x}$ can be calculated from equation (6). In case nitrate or ammonium is the nitrogen source (and hence, $d_{2}$ equals 0$), \gamma_{x}$ can also be determined from the assimilatory quotient $\left(\mathrm{AQ}\right.$, the quotient of moles of $\mathrm{CO}_{2}$ absorbed and oxygen evolved), which is the ratio of the flow of carbon dioxide and oxygen. This can be shown with the help of the solution for the flow of carbon dioxide, which is given by:

$$
\varphi_{3}=4 \frac{\varphi_{4}\left(d_{2} c_{1}-c_{2}\right)}{c_{2} \gamma_{x}}
$$

In case $\mathrm{d}_{2}=0$, it follows that

$$
\varphi_{3}=-4 \frac{\varphi_{4}}{\gamma_{x}}
$$

By using the definition of the AQ

$$
\mathrm{AQ}=-\frac{\varphi_{3}}{\varphi_{4}}
$$

we can rewrite equation (8) in the form of:

$$
\gamma_{x}=\frac{4}{\mathrm{AQ}}
$$

From this equation it is quite evident that in line measurements of AQ (and hence, $\gamma_{x}$ ) contain valuable information on the biochemical pathway that is synthesizing the cellular biomass. Because biomass is mainly composed of carbohydrate, protein and lipid, the values for $\gamma_{x}$ can range from 4.00 to 6.45 when the biomass would be exclusively composed of carbohydrate or lipid, respectively (Table 1 ). Based on the few phytoplankton species for which data were available to derive $\gamma_{x}$, Table 1 shows a rather limited range of values from 4.13 to 5.97. Furthermore, the derived $\mathrm{C} / \mathrm{N}$ ratios show a realistic variation around a Redfield ratio of 6.6 .

Under the restriction that oxygen-consuming reactions are negligible during photosynthesis, four electrons (with flow $\varphi_{\mathrm{e}}$ ) are needed to liberate one oxygen molecule from water. Applied to equation (8), and neglecting the direction of the flow, it follows:

$$
\varphi_{3}=\frac{\varphi_{\mathrm{e}}}{\gamma_{x}}
$$

$\varphi_{\mathrm{e}}$ is not directly observable, but its value is a function of the rate of electron transfer through all components of the Zscheme, ranging from PSII to Fd. With the advent of high quality fluorometers, it is now possible to routinely measure the quantum yield of fluorescence from PSII. The fluorescence quantum yield is now widely accepted to be largely dependent on the redox state of the first primary acceptor, $Q_{A}$, of PSII. The redox state of $Q_{\mathrm{A}}$, however, depends on all components that drive the photosynthetic reactions. In the following section, a model will be developed based on existing structures and known rate constants for all components of the Z-scheme. This model simulates the electron flow through the entire electron transport chain as a function of irradiance with a minimal time resolution of several hundreds of nanoseconds. The impact of photon flux density on the rate of carbon fixation can be examined after a conversion of the flux of electrons to carbon using $\gamma_{x}$. Adaptive responses are not taken into account explicitly, but can be understood as changes in either a change in photosynthetic reactions, or as a change in the pool-size of the main macromolecules of a cell, reflected by a

\begin{tabular}{|c|c|c|c|c|c|c|c|c|c|c|c|c|c|c|c|c|}
\hline \multirow[b]{2}{*}{ Species } & \multicolumn{3}{|c|}{$\%$ Ash-free dry weight } & \multicolumn{4}{|c|}{ Gram in percentage } & \multicolumn{4}{|c|}{ mol:mol C } & \multirow[b]{2}{*}{$\mathrm{C} / \mathrm{N}$ ratio } & \multicolumn{2}{|c|}{$\gamma_{x}$} & \multicolumn{2}{|c|}{$-\mathrm{AQ}$} \\
\hline & Protein & Carbohydrate & Lipid & $\mathrm{C}$ & $\mathrm{H}$ & $\mathrm{O}$ & $\mathrm{N}$ & C & $\mathrm{H}$ & $\mathrm{O}$ & $\mathrm{N}$ & & $\mathrm{NO}_{3}^{-}$ & $\mathrm{NH}_{4}^{+}$ & $\mathrm{NO}_{3}^{-}$ & $\mathrm{NH}_{4}^{+}$ \\
\hline \multicolumn{17}{|l|}{ Prasinophyceae } \\
\hline Tetraselmis maculata ${ }^{\mathrm{a}}$ & 68 & 20 & 4 & 47 & 6 & 26 & 12 & 1 & 1.63 & 0.42 & 0.22 & 4.48 & 5.92 & 4.13 & 0.68 & 0.97 \\
\hline Chlorophyceae & & & & & & & & & & & & & & & & \\
\hline Dunaliella salina ${ }^{\mathrm{a}}$ & 58 & 32 & 7 & 49 & 7 & 30 & 10 & 1 & 1.64 & 0.46 & 0.18 & 5.49 & 5.63 & 4.17 & 0.71 & 0.96 \\
\hline \multicolumn{17}{|l|}{ Bacillariophyceae } \\
\hline Chaetoceros sp. & 49 & 9 & 10 & 36 & 5 & 17 & 9 & 1 & 1.69 & 0.36 & 0.21 & 4.77 & 5.97 & 4.29 & 0.67 & 0.93 \\
\hline Coscinodiscus sp. ${ }^{\mathrm{b}}$ & 61 & 34 & 8 & 52 & 7 & 32 & 11 & 1 & 1.64 & 0.46 & 0.18 & 5.55 & 5.62 & 4.18 & 0.71 & 0.96 \\
\hline Phaeodactylum tricornutum ${ }^{\mathrm{b}}$ & 36 & 26 & 7 & 35 & 5 & 22 & 6 & 1 & 1.65 & 0.48 & 0.16 & 6.33 & 5.49 & 4.22 & 0.73 & 0.95 \\
\hline Skeletonema costatum ${ }^{\mathrm{a}}$ & 58 & 33 & 7 & 49 & 7 & 31 & 10 & 1 & 1.64 & 0.47 & 0.18 & 5.54 & 5.61 & 4.17 & 0.71 & 0.96 \\
\hline \multicolumn{17}{|l|}{ Chrysophyceae } \\
\hline Monochrysis lutheri ${ }^{\mathrm{a}}$ & 53 & 34 & 13 & 51 & 7 & 31 & 10 & 1 & 1.65 & 0.45 & 0.16 & 6.25 & 5.54 & 4.26 & 0.72 & 0.94 \\
\hline \multicolumn{17}{|l|}{ Dinophyceae } \\
\hline Amphidinium carteri $^{\mathrm{a}}$ & 36 & 39 & 23 & 52 & 7 & 31 & 7 & 1 & 1.67 & 0.46 & 0.11 & 9.21 & 5.3 & 4.43 & 0.75 & 0.90 \\
\hline 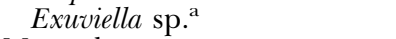 & 35 & 42 & 17 & 48 & 7 & 32 & 6 & 1 & 1.67 & 0.49 & 0.11 & 8.91 & 5.25 & 4.35 & 0.76 & 0.92 \\
\hline \multicolumn{17}{|l|}{ Myxophyceae } \\
\hline Agmenellum quadruplicatum ${ }^{\mathrm{a}}$ & 44 & 38 & 16 & 51 & 7 & 31 & 8 & 1 & 1.66 & 0.47 & 0.13 & 7.43 & 5.4 & 4.32 & 0.74 & 0.93 \\
\hline \multicolumn{17}{|l|}{ Macromolecular compounds } \\
\hline Carbohydrate & 0 & 100 & 0 & 44.4 & 6.2 & 49.4 & 0.0 & 1 & 1.67 & 0.83 & 0.00 & - & 4.00 & 4.00 & 1.00 & 1.00 \\
\hline Lipid & 0 & 0 & 100 & 69.1 & 10.0 & 17.9 & 0.6 & 1 & 1.74 & 0.19 & 0.01 & 132.06 & 5.39 & 5.33 & 0.74 & 0.75 \\
\hline Protein & 100 & 0 & 0 & 51.3 & 6.9 & 22.4 & 17.8 & 1 & 1.61 & 0.33 & 0.30 & 3.36 & 6.45 & 4.07 & 0.62 & 0.98 \\
\hline
\end{tabular}
change in $\gamma_{x}$.

TABLE 1. The elemental composition for the shown phytoplankton species was calculated from reported data on macromolecular composition as percentage ash-free dry weight, using the shown elemental composition of carbohydrate, lipid, and protein.

The $\mathrm{C} / \mathrm{N}$ ratio results are directly obtained from the elemental composition. Values for $\gamma_{x}$ and the assimilatory quotient (AQ) were derived using equations (6) and (10), respectively, both for growth on nitrate and ammonium.

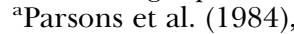

${ }^{\mathrm{b}}$ Morris (1981). 


\section{DESCRIPTION OF THE ELECTRON TRANSPORT MODEL}

The driving force behind photosynthetic electron transport is the absorption of light (in $\mu$ mol quanta. $\mathrm{m}^{-2} \cdot \mathrm{s}^{-1}$ ) by the core and peripheral antennae of PSII and PSI. The electrons are transported from water to the terminal electron acceptor Fd through both linear and non-linear pathways. Our model describes the rate of electron flow in $e^{-} \cdot \mathrm{ms}^{-1}$ in one photosynthetic redox chain containing all electron carriers required for the transfer of electrons from water through PSII to PSI and Fd.

The photosynthetic electron transport chain involves several components which may adopt different redox states: mobile electron carriers (plastoquinone $\mathrm{PQ}$, plastocyanin $\mathrm{PC}, \mathrm{Fd}$ ) as well as carriers grouped in protein complexes of PSII, cyt b6/f, and PSI. For simplicity we have assumed that, on average, all complexes of a given type (PSII, cyt b6/f, PSI) have the same kinetic characteristics, and each one of them are served by the same number of mobile carrier molecules. For a homogeneous system, the electron transport reactions can be described in terms of rate equations for the concentrations of the components in the individual redox states. For every possible redox state of a complex or a mobile electron carrier we can write down one balance equation, being an ordinary differential equation that, in the most general terms, reads

$$
\frac{\mathrm{d} C_{i}}{\mathrm{~d} t}=V_{i}^{+}\left(C_{i}, k_{j}\right)-V_{i}^{-}\left(C_{i}, k_{j}\right)
$$

where $C_{i}$ is the concentration of that component of the electron transport chain, which adopts the $i$ th redox state. The right-hand side of the differential equation is composed of two parts, one for the overall rate of production $\left(V_{i}^{+}\right)$and one for the overall rate of consumption $\left(V_{i}^{-}\right)$. Many processes of the electron transport chain can contribute to the production and to the depletion of a given $C_{i}$. The overall rates $V_{i}^{+}$and $V_{i}^{-}$, therefore, consist of sums of functions, each one of them represent the rate of one individual reaction (rate constant: $k_{j}$ ). The flow diagrams of reactions chains related to PSII, cyt b6/f, PSI are presented in Figs. 2-4, and the individual reactions will be described in more detail below. The details of translating the flow diagrams into equations are given in Tables 3-8.

All electron transfer reactions within the PSII, cyt b6/f, and PSI complexes are of first order (except the oxidation of the primary electron donor of PSI, which is of second order). Electron transfer between a protein complex and a mobile electron carrier is described by equations of mass action type with bimolecular rate constants. The summation of $C_{i}$ (equation (12)) over all possible states $i$ of a component $y$ yield the total concentration of that component in the system:

$$
C_{y}=\sum_{(i, y)} C_{i}, \quad y=\text { PSII, cyt b6/f, PSI, PQ, PC, Fd }
$$

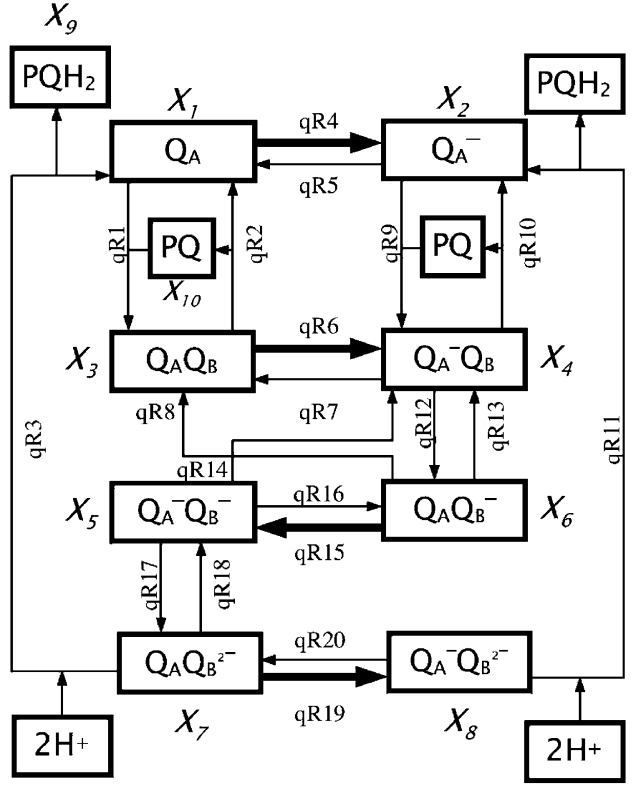

FIG. 2. The catalytic cycle of PSII. Each rectangle represents a particular kinetic state determined by the redox state of the involved electron carriers: $Q_{A}$ and $Q_{B}$, the primary and secondary quinone acceptors; $\mathrm{PQ}$, plastoquinone; $\mathrm{PQH}_{2}$, plastoquinol. $P Q$ is the oxidized form of the plastoquinone pool. The redox states of $Q_{A}$ and $Q_{B}$ are given in the superscripts. The charge separation steps at PSII are indicated by thick arrows. Designations at the boxes and at the arrows correspond to the state variables (Table 3) and reaction rates (first column of Table 7), respectively. Please note that in case of multiple appearance of a particular box the state variable is identified once only.

In the present work, the stoichiometry of the components was taken to be

$$
\begin{aligned}
& C_{\mathrm{PSII}}: C_{\mathrm{b} 6 / \mathrm{f}}: C_{\mathrm{PSI}}: C_{\mathrm{PQ}}: C_{\mathrm{PC}}: C_{\mathrm{Fd}} \\
& \quad=1: 1: 1: 4: 1: 1
\end{aligned}
$$

for the numerical simulations of fluorescence induction and P-E curves. For simplifying simulations, we have introduced normalized state variables $X_{i}$ and model parameters $k_{x j}$ by rescaling both, the concentrations $C_{i}$ and the rate constants $k_{j}$ with a appropriate power of a constant concentration $C_{0}$ :

$$
X_{i}=\frac{C_{i}}{C_{0}}, \quad k_{x j}=k_{j} C_{0}^{v_{j}-1}
$$

where $v_{j}$ is the order of the reaction $j$. Because of the simple stoichiometry of PSII, cyt b6/f, and PSI complexes (1:1:1, see equation (14)) we rescaled $C_{i}$ and $k_{j}$ with the total concentrations of the individual protein complexes:

$$
C_{0}=C_{\mathrm{PSII}}=C_{\mathrm{b} 6 / \mathrm{f}}=C_{\mathrm{PSI}}
$$

Inserting equation (16) into equation (15) yields simple interpretations of $X_{i}$ and $k_{x j}$. In case that $i$ denotes one of the possible states of PSII (cyt b6/f, PSI), the $X_{i}$ represents the fraction of PSII units (cyt b6/f complexes, PSI units) in the $i$ th redox state. For a homogeneous PSII (cyt b6/f, PSI) population, the fraction $X_{i}$ corresponds to the probability for the $i$ th state of the com- 


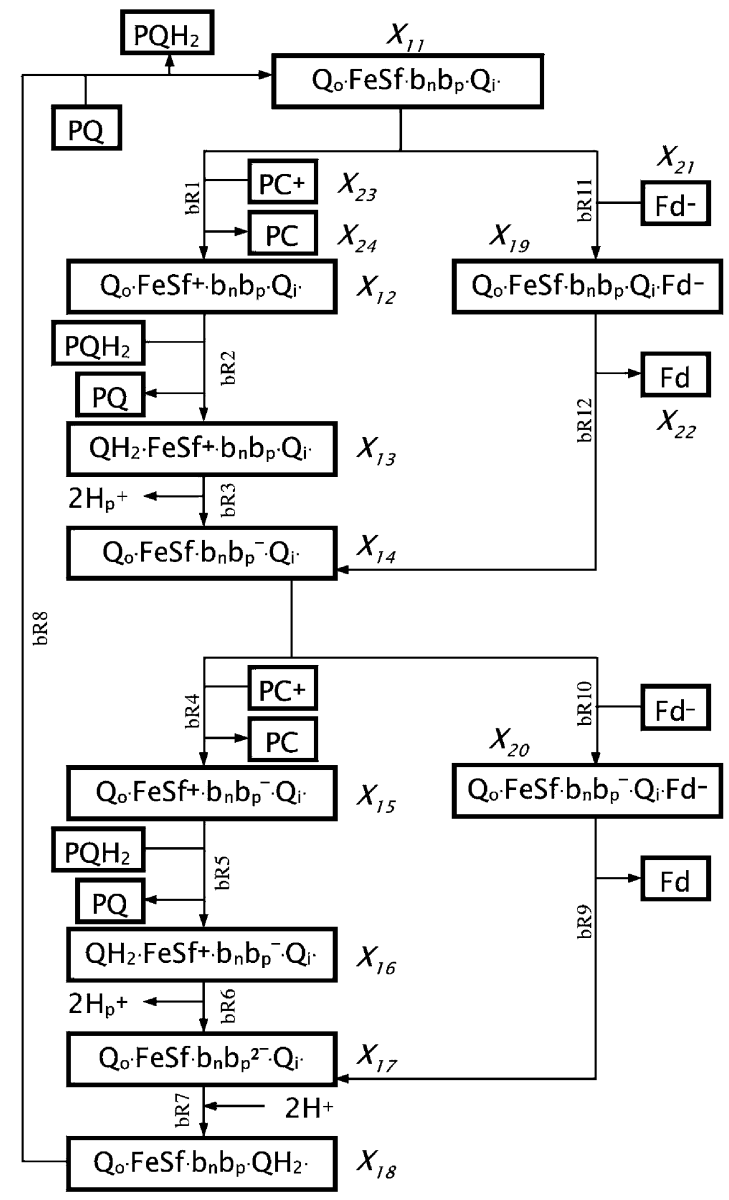

FIG. 3. The catalytic cycle of the cytochrome b6/f complex. The complex is here represented as $Q_{0} F_{e S f b} b_{n} Q_{i}$, which involves the following carriers: $Q_{o}$ and $Q_{i}$, the quinone oxidizing and reducing sites; FeSf, the Rieske iron-sulfur center and $\mathrm{f}$, cytochrome $f ; b_{p} b_{n}$, cytochromes b6 at the positive (lumen) or negative (stroma) side of the thylakoid membrane. Other carriers involved are: PC, plastocyanin; PQ, oxidized plastoquinon; $\mathrm{PQH}_{2}$, reduced plastoquinol; Fd, ferredoxin. The redox states of the carriers are given in the superscripts. Designations at the boxes and at the arrows correspond to the state variables (Table 3 ) and reaction rates (second column of Table 7), respectively. Note, that the reactions bR9 through bR12 represent two possible pathways involved in cyclic PSI electron transport. Please note that in case of multiple appearance of a particular box the state variable is identified once only.

plex. Otherwise if $i$ denotes the reduced (oxidized) state of an electron carrier, the $X_{i}$ represent the number of reduced (oxidized) carriers per served photosystem, i.e. PSII for PQ and PSI for PC, Fd. The parameters $k_{x j}$ represent the inverse of the characteristic times for the individual electron transfer reactions $j$. In terms of the normalized quantities the set of rate equations (12) is given by

$$
\frac{\mathrm{d} X_{i}}{\mathrm{~d} t}=V_{i}^{+}\left(X_{i}, k_{x j}\right)-V_{i}^{-}\left(X_{i}, k_{x j}\right)
$$

with dimensionless state variables $X_{i}$ and normalized rate constants $k_{x j}$ in $\mathrm{m} \mathrm{s}^{-1}$. The set of state variables and rate constants used for all simulations are listed in

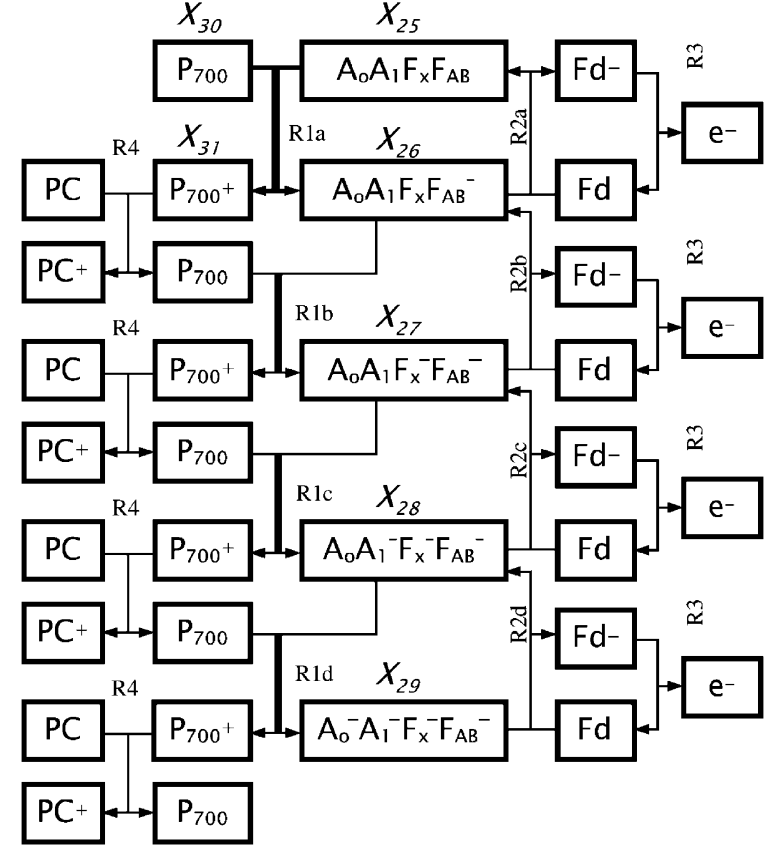

FIG. 4. Electron transfer in PSI. The PSI complex is here represented as the primary electron donor $\mathrm{P}_{700}$ (a chl dimer) and the acceptor complex $A_{o} A_{1} F_{x} F_{A B}$, which involves the following carriers: $\mathrm{A}_{\mathrm{o}}$, a single chl $a ; \mathrm{A}_{1}$, a phylloquinone (vitamin $\mathrm{K} 1$ ); $\mathrm{F}_{\mathrm{x}}$, the iron-sulfur cluster; $\mathrm{F}_{\mathrm{AB}}$, the terminal iron-sulfur acceptors. The redox states of the carriers are given in the superscripts. Designations at the boxes and at the arrows correspond to the state variables (Table 3) and reaction rates (third column of Table 7), respectively. Please note that in case of multiple appearance of a particular box the state variable is identified once only.

Tables 3 and 4, respectively. In Table 4 we introduced new symbols for the rate constants $k_{x j}$, which describe the type of reactions involved. If not otherwise stated explicitly, the formulation of the individual reactions and values for rate constants were based on values in the literature (Crofts and Wraight 1983, Robinson and Crofts 1983, Baker and Webber 1987, Cramer and Knaff 1989, Whitmarsh and Govindjee 1995, Hippler et al. 1998, Lazár 1999).

The description of photon absorption and charge separation at PSII in the framework of model Equations 17 required the evaluation of the reduction rates for the primary quinone acceptor $Q_{A}$ in every possible open state of PSII complex (oxidized $Q_{\mathrm{A}}$ ). The rate of $Q_{A}$ reduction depends on several parameters, for example photon flux density, absorption cross-section of the antenna of PSII units, rate constants of exciton trapping and radical pair creation (primary charge separation). We used the exciton-radical-pair model of Lavergne and Trissl (1995) to describe the radical pair decay in an open centre through stabilization of charge, i.e. reduction of $Q_{A}$. The outcome of this model results in a simple analytical expression for the photochemical yield as a function of any of the possible states of open PSII units. The photochemical yield of PSI is not described as a function of antennae characteristics, because its oxidized state is as good a quenc- 
TABle 2. The number of $\operatorname{chl} a, \operatorname{chl} b$, and $\operatorname{chl}(a+b)$ molecules in both PSII and PSI were modelled based on the pigmentbinding proteins (Simpson and Knoetzel 1996) of PSII (CP43 +47 containing 37 chl $a$; Lhcb3, Lhcb4, Lhcb5, Lhcb6 each containing $14 \mathrm{chl} a$ and $8.45 \mathrm{chl} b$; and trimers of Lhcb1 plus Lhcb2 each containing $52 \mathrm{chl} a$ and $38.5 \mathrm{chl} b)$ and of PSI (Core with $90 \mathrm{chl} a$; Lhcal, Lhca2, Lhca3, Lhca4 each with $10 \mathrm{chl} a$ and $2.8 \mathrm{chl} b$; and trimers of Lhcb1 plus Lhcb2 each with $52 \mathrm{chl} a$ and $38.5 \mathrm{chl} b$ ).

\begin{tabular}{|c|c|c|c|c|c|c|c|c|c|c|c|c|}
\hline \multirow[b]{2}{*}{ Scenario } & \multicolumn{3}{|c|}{ Number of proteins per PSII } & \multicolumn{3}{|c|}{$\operatorname{chl} a / b$ molecules per PSII } & \multicolumn{3}{|c|}{ Number of proteins per PSI } & \multicolumn{3}{|c|}{ chl $a / b$ molecules per PSI } \\
\hline & $\mathrm{CP} 43+47$ & $\begin{array}{l}\text { Lhcb3 to } \\
\text { Lhcb6 }\end{array}$ & $\begin{array}{l}\text { Trimers of } \\
\text { Lhcb } 1 / b 2\end{array}$ & $\operatorname{chl} a$ & $\operatorname{chl} b$ & $\operatorname{chl} a+b$ & Core & $\begin{array}{l}\text { Lhcal to } \\
\text { Lhca4 }\end{array}$ & $\begin{array}{l}\text { Trimers of } \\
\text { Lhcbl/b2 }\end{array}$ & $\operatorname{chl} a$ & $\operatorname{chl} b$ & $\operatorname{chl} a+b$ \\
\hline 1 & 1 & 4 & 4 & 261 & 158 & 419 & 90 & 8 & 2 & 254 & 85 & 339 \\
\hline 2 & 1 & 4 & 3.5 & 240 & 143 & 383 & 90 & 8 & 1 & 212 & 54 & 266 \\
\hline 3 & 1 & 4 & 3 & 219 & 127 & 346 & 90 & 8 & 0 & 170 & 23 & 193 \\
\hline 4 & 1 & 4 & 2.5 & 198 & 112 & 310 & 90 & 7 & 0 & 160 & 20 & 180 \\
\hline 5 & 1 & 4 & 2 & 177 & 96 & 273 & 90 & 6 & 0 & 150 & 17 & 167 \\
\hline 6 & 1 & 4 & 1.5 & 156 & 81 & 237 & 90 & 5 & 0 & 140 & 14 & 154 \\
\hline 7 & 1 & 4 & 1 & 135 & 65 & 200 & 90 & 4 & 0 & 130 & 11 & 141 \\
\hline 8 & 1 & 4 & 0.5 & 114 & 50 & 164 & 90 & 3 & 0 & 120 & 9 & 129 \\
\hline 9 & 1 & 4 & 0 & 93 & 34 & 127 & 90 & 2 & 0 & 110 & 6 & 116 \\
\hline
\end{tabular}

Nine scenarios for PSII and PSI were chosen with varying amounts of peripheral antennae sizes as indicated by the numbers of chl $a$, chl $b$ and $\operatorname{chl}(a+b)$.

her of excitation energy as is its reduced form. Therefore, the photochemical yield of PSI can be set to 1 , its maximum value. The auxiliaries and constants used for calculation of the rates of stable charge separations at PSII and PSI are given in Tables 5 and 6. Subsequent to the equations governing photon absorption and charge separation at PSII, the reactions of the electron transport pathway will be presented in three main sections: from PSII to plastoquinol $\left(\mathrm{PQH}_{2}\right)$, from $\mathrm{PQH}_{2}$ to $\mathrm{PC}$ (including the Q-cycle of the cyt b6/f complex), and from PSI to Fd. The rates for the reactions of the three sections contributing to the right-hand side of the equations (17) are given in Table 7. The combination of these rates according to the flow diagrams shown in Figs. 2-4 yields the complete set of ordinary differential equations (17) in terms of the

TABLE 3. Listing of state variables and their initial values (at $t=0$ ) used in the model.

\begin{tabular}{|c|c|c|c|}
\hline Variable & Unit & Initial value & Definition \\
\hline$X_{1}$ & None & $\frac{x}{x+1}$ & Fraction of PSIIs with oxidized $Q_{A}$ and vacant $Q_{B}$ site \\
\hline$X_{2}$ & None & 0 & Fraction of PSIIs with reduced $Q_{\mathrm{A}}$ and vacant $Q_{\mathrm{B}}$ site \\
\hline$X_{3}$ & None & $\frac{1}{x+1}$ & Fraction of PSIIs with oxidized $\mathrm{Q}_{\mathrm{A}}$ and oxidized $\mathrm{Q}_{\mathrm{B}}$ \\
\hline$X_{4}$ & None & 0 & Fraction of PSIIs with reduced $Q_{A}$ and oxidized $Q_{B}$ \\
\hline$X_{5}$ & None & 0 & Fraction of PSIIs with reduced $\widetilde{Q}_{\mathrm{A}}$ and reduced $\mathrm{Q}_{\mathrm{B}}$ \\
\hline$X_{6}$ & None & 0 & Fraction of PSIIs with oxidized $\widetilde{Q}_{\mathrm{A}}$ and reduced $\widetilde{\mathrm{Q}}_{\mathrm{B}}$ \\
\hline$X_{7}$ & None & 0 & Fraction of PSIIs with oxidized $\widetilde{Q}_{A}$ and doubly reduced $Q_{B}$ \\
\hline$X_{8}$ & None & 0 & Fraction of PSIIs with reduced $\widetilde{Q}_{\mathrm{A}}$ and doubly reduced $\widetilde{Q}_{\mathrm{B}}$ \\
\hline$X_{9}$ & None & 0 & Number of plastoquinol per PSII \\
\hline$X_{10}$ & None & 4 & Number of plastoquinone per PSII \\
\hline$X_{11}$ & None & 1 & Fraction of cyt b6/f complexes in neutral state \\
\hline$X_{12}$ & None & 0 & Fraction of cyt b6/f complexes with oxidized cyt $\mathrm{f}$ \\
\hline$X_{13}$ & None & 0 & Fraction of cyt b6/f complexes with reduced $Q_{o}$ site \\
\hline$X_{14}$ & none & 0 & Fraction of cyt $\mathrm{b} 6 / \mathrm{f}$ complexes with one of the $b$ hemes in reduced state \\
\hline$X_{15}$ & None & 0 & As $X_{14}$ additionally with oxidized cyt $\mathrm{f}$ \\
\hline$X_{16}$ & None & 0 & As $X_{15}$ additionally with reduced $Q_{0}$ site \\
\hline$X_{17}$ & None & 0 & Fraction of cyt b6/f complexes with both $b$ hemes in reduced state \\
\hline$X_{18}$ & None & 0 & Fraction of cyt b6/f complexes with doubly protonated $Q_{i}$ site \\
\hline$X_{19}$ & None & 0 & As $X_{11}$ with reduced ferredoxin at $Q_{\mathrm{i}}$ site \\
\hline$X_{20}$ & None & 0 & As $X_{14}$ with reduced ferredoxin at $\widetilde{Q}_{\mathrm{i}}$ site \\
\hline$X_{21}$ & None & 0 & Number of reduced ferredoxin per PSI \\
\hline$X_{22}$ & None & 1 & Number of neutral ferredoxin per PSI \\
\hline$X_{23}$ & None & 0 & Number of oxidized plastocyanin per PSI \\
\hline$X_{24}$ & None & 1 & Number of neutral plastocyanin per PSI \\
\hline$X_{25}$ & None & 1 & Fraction of PSIs with $A_{o} A_{1} F_{x} F_{A B}$ in neutral state \\
\hline$X_{26}$ & None & 0 & Fraction of PSIs with reduced $\mathrm{F}_{\mathrm{AB}}$ \\
\hline$X_{27}$ & None & 0 & As $X_{26}$ additionally with reduced $\mathrm{F}_{\mathrm{x}}$ \\
\hline$X_{28}$ & None & 0 & As $X_{27}$ additionally with reduced $A_{1}$ \\
\hline$X_{29}$ & None & 0 & As $X_{28}$ additionally with reduced $\mathrm{A}_{\mathrm{o}}$ \\
\hline$X_{30}$ & None & 1 & Fraction of PSIs with P700 in neutral state \\
\hline$X_{31}$ & None & 0 & Fraction of PSIs with oxidized P700 \\
\hline
\end{tabular}

For the definition of $x$, see equation (24). 
TABLE 4. Listing of rate constants and their values used in the model.

\begin{tabular}{|c|c|c|c|c|}
\hline Rate constant & Unit & Value & Reactions & Process \\
\hline$b k 1$ & $\mathrm{~m} \mathrm{~s}^{-1}$ & 5 & bR1, bR4 & Oxidation of b6/f by $\mathrm{PC}^{+}$ \\
\hline$b k 2$ & $\mathrm{~m} \mathrm{~s}^{-1}$ & 10 & bR2, bR5 & Re-oxidation of $\mathrm{PQH}_{2}$ by b6/f \\
\hline$b k 3$ & $\mathrm{~m} \mathrm{~s}^{-1}$ & 0.99 & bR3, bR6 & Lumenal proton release by $\mathrm{b} 6 / \mathrm{f}$ \\
\hline$b k 4$ & $\mathrm{~m} \mathrm{~s}^{-1}$ & 1 & bR7 & Stromal proton binding by b6/f \\
\hline$b k 5$ & $\mathrm{~m} \mathrm{~s}^{-1}$ & 5 & bR8 & Reduction of $P Q$ at $Q_{i}$ site of $b 6 / f$ \\
\hline$b k 6$ & $\mathrm{~m} \mathrm{~s}^{-1}$ & 2 & bR9, bR12 & Release of Fd from b6/f \\
\hline$k a b E$ & $\mathrm{~m} \mathrm{~s}^{-1}$ & 1.733 & qR17 & Electron transfer between $Q_{A}$ and $Q_{B}$ \\
\hline$k a b O$ & $\mathrm{~m} \mathrm{~s}^{-1}$ & 4.621 & $\mathrm{qR} 12$ & Electron transfer between $\widetilde{Q}_{\mathrm{A}}$ and $\widetilde{Q}_{\mathrm{B}}$ \\
\hline kav & $\mathrm{m} \mathrm{s}^{-1}$ & 0.34 & $\mathrm{qR} 2, \mathrm{qR} 10$ & Release of PQ from PSII \\
\hline kbackA & $\mathrm{m} \mathrm{s}^{-1}$ & $2.567 \times 10^{-4}$ & $\mathrm{qR} 5, \mathrm{qR} 7, \mathrm{qR} 16, \mathrm{qR} 20$ & Charge recombination in PSII \\
\hline kbackB & $\mathrm{m} \mathrm{s}^{-1}$ & $2.773 \times 10^{-5}$ & qR8, qR14 & Charge recombination in PSII \\
\hline$k b a E$ & $\mathrm{~m} \mathrm{~s}^{-1}$ & 0.0347 & $\mathrm{gR} 18$ & Electron transfer between $Q_{A}$ and $Q_{B}$ \\
\hline$k b a O$ & $\mathrm{~m} \mathrm{~s}^{-1}$ & 0.2718 & qR13 & Electron transfer between $\widetilde{Q}_{\mathrm{A}}$ and $\widetilde{Q}_{\mathrm{B}}$ \\
\hline$k c$ & $\mathrm{~m} \mathrm{~s}^{-1}$ & 0.03 & bR10, bR11 & Docking of $\mathrm{Fd}^{-}$to $\mathrm{b} 6 / \mathrm{f}$ \\
\hline$k_{P 700}$ & $\mathrm{~m} \mathrm{~s}^{-1}$ & 6.9 & R4 & PSI reduction of PC \\
\hline kpqh2 & $\mathrm{m} \mathrm{s}^{-1}$ & 2 & qR3, qR11 & Release of $\mathrm{PQH}_{2}$ from PSII \\
\hline$k_{P S I}^{1}$ & $\mathrm{~m} \mathrm{~s}^{-1}$ & 0.2 & R2a-d & Reduction of Fd by PSI \\
\hline kterm & $\mathrm{m} \mathrm{s}^{-1}$ & 0.12 & R3 & Terminal Fd re-oxidation \\
\hline$k v a$ & $\mathrm{~m} \mathrm{~s}^{-1}$ & 0.86 & qR1, qR9 & Docking of PQ to PSII \\
\hline
\end{tabular}

TABLE 5. Equations used for the calculation of the $Q_{A}$ reduction rates (qR4, qR6, qR15, qR19 in Table 7) and the fluorescence yield.

\begin{tabular}{|c|c|c|c|}
\hline Auxiliary & Unit & Definition & Comment \\
\hline $\operatorname{Exc}_{I I} \cdot \Phi_{\mathrm{PSII}, \mathrm{i}}$ & $\mathrm{m} \mathrm{s}^{-1}$ & $\left(\sigma_{\mathrm{chl} a} \mathrm{~N}_{a \mathrm{II}}+\sigma_{\mathrm{chl} l} \mathrm{~N}_{b \mathrm{II}}\right)$ PFD cf A $\frac{X_{i}}{1+\mathrm{J} \Sigma_{i} X_{i}}$ & $\begin{array}{l}\mathrm{Q}_{\mathrm{A}} \text { reduction rate in open PSII state } i, i=1,3,6,7 \\
\text { (Table 3). Product of equations }(20) \text { and }(22)\end{array}$ \\
\hline $\operatorname{Exc}_{I} \cdot \Phi_{\mathrm{PSI}}$ & $\mathrm{m} \mathrm{s}^{-1}$ & $\left(\sigma_{\mathrm{chl} a} \mathrm{~N}_{a \mathrm{I}}+\sigma_{\mathrm{chl} l} \mathrm{~N}_{b \mathrm{I}}\right)$ PFD cf 1 & $\begin{array}{l}\text { Reduction rate for the FeS acceptor complex } \\
A_{\mathrm{O}} A_{1} F_{x} F_{A B} \text {. }\end{array}$ \\
\hline$\Phi_{\mathrm{f}}$ & None & $\frac{\mathrm{B}+\mathrm{Cq}}{1+\mathrm{Jq}}, \quad \mathrm{q}=\Sigma_{i} X_{i}, \quad i=1,3,6,7$ & $\begin{array}{l}\text { Product of equation (21) and } \Phi_{\mathrm{PSI}}=1 \\
\text { Fluorescence yield }\end{array}$ \\
\hline A & None & $\frac{\alpha_{\mathrm{p}}\left(k_{\mathrm{UU}}+\beta+k_{\text {loss }}\right)}{}$ & \multirow[t]{2}{*}{$\begin{array}{l}\text { Parameter in } \operatorname{Exc}_{I I} \cdot \Phi_{\text {PSII,i. }} \text {. Depends on biophysical } \\
\text { rate constants for PSII (Table } 6 \text { ) }\end{array}$} \\
\hline & & $\overline{\left(\beta+k_{\text {loss }}\right)\left(k_{\mathrm{UU}}+\alpha_{\mathrm{p}}+\alpha_{\mathrm{d}}+k_{\text {loss }}\right)}$ & \\
\hline B & None & $\frac{k_{\mathrm{rad}}}{\left(\beta+k_{\mathrm{loss}}\right)}$ & $\begin{array}{l}\text { Parameter in } \Phi_{\mathrm{f}} \text {. Depends on biophysical rate } \\
\text { constants } \\
\text { for PSII (Table 6) }\end{array}$ \\
\hline \multirow[t]{2}{*}{$\mathrm{C}$} & None & $k_{\mathrm{rad}}\left(\alpha_{\mathrm{p}}+\alpha_{\mathrm{d}}-\beta\right)$ & \multirow{2}{*}{$\begin{array}{l}\text { Parameter in } \Phi_{\mathrm{f}} \text {. Depends on biophysical rate } \\
\text { constants } \\
\text { for PSII (Table } 6 \text { ) }\end{array}$} \\
\hline & & $\left(\beta+k_{\text {loss }}\right)\left(k_{\mathrm{UU}}+\alpha_{\mathrm{p}}+\alpha_{\mathrm{d}}+k_{\text {loss }}\right)$ & \\
\hline \multirow[t]{2}{*}{$\mathrm{J}$} & None & $k_{\mathrm{UU}}\left(\alpha_{\mathrm{p}}+\alpha_{\mathrm{d}}-\beta\right)$ & \multirow{2}{*}{$\begin{array}{l}\text { Connectivity parameter in } \operatorname{Exc}_{I I} \cdot \Phi_{\mathrm{PSII}, \mathrm{i}} \text { and } \Phi_{\mathrm{f}} \\
\text { Depends on biophysical rate constants for PSII } \\
\text { (Table } 6 \text { ) }\end{array}$} \\
\hline & & $\overline{\left(\beta+k_{\text {loss }}\right)\left(k_{\mathrm{UU}}+\alpha_{\mathrm{p}}+\alpha_{\mathrm{d}}+k_{\text {loss }}\right)}$ & \\
\hline \multirow[t]{2}{*}{$\alpha_{\mathrm{p}}$} & $\mathrm{n} \mathrm{s}^{-1}$ & $k_{\mathrm{t}}^{\mathrm{ox}} k_{2}$ & \multirow[t]{2}{*}{$\begin{array}{l}\text { Term in A, C, and J. Involves the biophysical } \\
\text { rate constants for PSII (Table } 6 \text { ) }\end{array}$} \\
\hline & & $\overline{k_{-1}^{\mathrm{ox}}+k_{2}+k_{\mathrm{d}}^{\mathrm{ox}}}$ & \\
\hline \multirow[t]{2}{*}{$\alpha_{\mathrm{d}}$} & $\mathrm{ns}^{-1}$ & $k_{\mathrm{t}}^{\text {ox }} k_{\mathrm{d}}^{\text {ox }}$ & \multirow[t]{2}{*}{$\begin{array}{l}\text { Term in A, C, and J. Involves the biophysical } \\
\text { rate constants for PSII (Table } 6 \text { ) }\end{array}$} \\
\hline & & $k_{-1}^{\mathrm{ox}}+k_{2}+k_{\mathrm{d}}^{\mathrm{ox}}$ & \\
\hline$\beta$ & $\mathrm{n} \mathrm{s}^{-1}$ & $\frac{k_{\mathrm{t}}^{\mathrm{red}} k_{\mathrm{d}}^{\mathrm{red}}}{k_{-1}^{\mathrm{red}}+k_{\mathrm{d}}^{\mathrm{red}}}$ & $\begin{array}{l}\text { Term in A, B, C, and J. Involves the biophysical } \\
\text { rate constants for PSII (Table } 6 \text { ) }\end{array}$ \\
\hline
\end{tabular}

individual reactions involved in the photosynthetic electron transport chain. The differential equations for the individual state variables are listed in Table 8.
Photon absorption. The photons are absorbed by the antennae pigments, and the excitation energy is transferred to the two reaction centers, PSII and PSI. 
TABLE 6. Biophysical rate constants for PSII used in the exciton-radical-pair model of Trissl and Lavergne (1994).

\begin{tabular}{|c|c|c|c|}
\hline Constant & Value & Unit & Definition \\
\hline$k_{\mathrm{t}}^{\mathrm{ox}}$ & $\frac{540}{\mathrm{~N}_{\mathrm{aII}}+\mathrm{N}_{\mathrm{bII}}}$ & $\mathrm{ns}^{-1}$ & $\begin{array}{l}\text { Trapping constant for open PSII centers. Depends on the number of chl } a \\
\text { and chl } b \text { molecules in PSII (Table 2) }\end{array}$ \\
\hline$k_{2}$ & 2.3 & $\mathrm{n} \mathrm{s}^{-1}$ & Reduction of $Q_{\mathrm{A}}$ \\
\hline$k_{-1}^{\mathrm{ox}}$ & 0.3 & $\mathrm{n} \mathrm{s}^{-1}$ & Charge recombination in PSII units with open centers \\
\hline$k_{\mathrm{d}}^{\mathrm{ox}}$ & 0.001 & $\mathrm{n} \mathrm{s}^{-1}$ & Non-radiative losses of the radical pair in open centers \\
\hline$k_{\mathrm{t}}^{\mathrm{red}}$ & $\frac{84.6}{\mathrm{~N}_{\mathrm{aII}}+\mathrm{N}_{\mathrm{bII}}}$ & $\mathrm{ns}^{-1}$ & $\begin{array}{l}\text { Trapping constant for closed PSII centers. Depends on the number of chl } a \text { and } \\
\text { chl } b \text { molecules in PSII (Table 2) }\end{array}$ \\
\hline$k_{-1}^{\mathrm{red}}$ & 0.34 & $\mathrm{n} \mathrm{s}^{-1}$ & Charge recombination in PSII units with closed centers \\
\hline$k_{\mathrm{d}}^{\mathrm{red}}$ & 0.99 & $\mathrm{n} \mathrm{s}^{-1}$ & Non-radiative losses of the radical pair in closed centers \\
\hline$k_{\mathrm{UU}}$ & 2.6 & $\mathrm{n} \mathrm{s}^{-1}$ & Interunit exciton transfer \\
\hline$k_{\text {loss }}$ & 0.45 & $\mathrm{n} \mathrm{s}^{-1}$ & Exciton losses \\
\hline$k_{\text {rad }}$ & 0.084 & $\mathrm{n} \mathrm{s}^{-1}$ & Radiative antennae decay \\
\hline
\end{tabular}

It is well known, that the number of the light absorbing pigments changes as a function of the availability of light. The pigments of both PSII and PSI are bound to different proteins, and their structure and binding capacities are known (Simpson and Knoetzel 1996). Based on this review, we formulated nine different scenarios for the number of chl $a$ and chl $b$ molecules in PSII and PSI (Table 2). These scenarios reflect the antenna organization in green algae, and could be extended by inclusion of chl $c$ or phycobilisomes containing complexes.

The optical cross sections of chl $a\left(\sigma_{\operatorname{chl} a}\right)$ and $\operatorname{chl} b$ $\left(\sigma_{\mathrm{chl} b}\right)$ are $8.6749 \times 10^{-21} \mathrm{~m}^{2} \mathrm{chl} a^{-1}$ and $9.1222 \times$ $10^{-21} \mathrm{~m}^{2}$ chl $b^{-1}$, respectively (Bidigare et al. 1990). The optical cross-sections for PSII $\left(\sigma_{\text {PSII }}\right)$ and PSI $\left(\sigma_{\text {PSI }}\right)$ can now be calculated with:

$$
\begin{gathered}
\sigma_{\mathrm{PSII}}=\sigma_{\mathrm{chl} a} \mathrm{~N}_{a \mathrm{II}}+\sigma_{\mathrm{chl} b} \mathrm{~N}_{b \mathrm{II}} \\
\sigma_{\mathrm{PSI}}=\sigma_{\mathrm{chl} a} \mathrm{~N}_{a \mathrm{I}}+\sigma_{\mathrm{chl} b} \mathrm{~N}_{b \mathrm{I}}
\end{gathered}
$$

TABLE 7. Reaction rates for the reactions involved in electron transfer in PSII (Fig. 2), cyt b6/f complex (Fig. 3), and

\begin{tabular}{|c|c|c|}
\hline PSII & cyt b6/f & PSI \\
\hline $\begin{array}{l}\mathrm{qR} 1=k v a X_{1} X_{10} \\
\mathrm{qR} 2=k a v X_{3} \\
\mathrm{qR} 3=k p q h 2 X_{7} \\
\mathrm{qR} 4=\operatorname{Exc}_{\mathrm{II}} \Phi_{\mathrm{PSII}, 1} \\
\mathrm{qR} 5=k b a c k A X_{2} \\
\mathrm{qR} 6=\operatorname{Exc}_{\mathrm{II}} \Phi_{\mathrm{PSII}, 3} \\
\mathrm{qR} 7=k b a c k A X_{4} \\
\mathrm{qR} 8=k b a c k B X_{6} \\
\mathrm{qR} 9=k v a X_{2} X_{10} \\
\mathrm{qR} 10=k a v X_{4} \\
\mathrm{qR} 11=k p q h 2 X_{8} \\
\mathrm{qR} 12=k a b O X_{4} \\
\mathrm{qR} 13=k b a O X_{6} \\
\mathrm{qR} 14=k b a c k B X_{5} \\
\mathrm{qR} 15=\operatorname{Exc}{ }_{\text {III }} \Phi_{\mathrm{PSII}, 6} \\
\mathrm{qR} 16=k b a c k A X_{5} \\
\mathrm{qR} 17=k a b E X_{5} \\
\mathrm{qR} 18=k b a E X_{7} \\
\mathrm{qR} 19=\operatorname{Exc}_{\mathrm{II}} \Phi_{\mathrm{PSII}, 7} \\
\mathrm{qR} 20=k b a c k A X_{8}\end{array}$ & $\begin{array}{l}\mathrm{bR} 1=b k 1 X_{23} X_{11} \\
\text { bR2 }=b k 2 X_{12} X_{9} \\
\text { bR3 }=b k 3 X_{13} \\
\text { bR4 }=b k 1 X_{14} X_{23} \\
\text { bR5 }=b k 2 X_{15} X_{9} \\
\text { bR6 }=b k 3 X_{16} \\
\text { bR7 }=b k 4 X_{17} \\
\text { bR8 }=b k 5 X_{18} X_{10} \\
\text { bR9 }=b k 6 X_{20} \\
\text { bR10 }=k c X_{14} X_{21} \\
\text { bR11 }=k c X_{11} X_{21} \\
\text { bR12 }=b k 6 X_{19}\end{array}$ & $\begin{array}{l}\mathrm{R} 1 \mathrm{a}=\operatorname{Exc}_{I} \Phi_{\mathrm{PSI}} X_{30} X_{25} \\
\mathrm{R} 1 \mathrm{~b}=\operatorname{Exc}_{1} \Phi_{\mathrm{PSI}} X_{30} X_{26} \\
\mathrm{R} 1 \mathrm{c}=\operatorname{Exc}_{I} \Phi_{\mathrm{PSI}} X_{30} X_{27} \\
\mathrm{R} 1 \mathrm{~d}=\operatorname{Exc}_{\mathrm{I}} \Phi_{\mathrm{PSI}} X_{30} X_{28} \\
\mathrm{R} 2 \mathrm{~d}=k_{P S I} X_{29} X_{22} \\
\mathrm{R} 2 \mathrm{c}=k_{P S I} X_{28} X_{22} \\
\mathrm{R} 2 \mathrm{~b}=k_{P S I} X_{27} X_{22} \\
\mathrm{R} 2 \mathrm{a}=k_{P S I} X_{26} X_{22} \\
\mathrm{R} 3=k \text { term } X_{21} \\
\mathrm{R} 4=k_{P 700} X_{24} X_{31}\end{array}$ \\
\hline
\end{tabular}
PSI (Fig. 4).

Equations used for the calculation of qR4, qR6, qR15, and qR19 are given in Table 5 . where $\mathrm{N}_{a \mathrm{II}}, \mathrm{N}_{b \mathrm{II}}, \mathrm{N}_{a \mathrm{I}}$, and $\mathrm{N}_{b \mathrm{I}}$ are the number of chl $a$ and chl $b$ molecules in PSII and PSI. The number of $\operatorname{chl} a$ and chl $b$ molecules in PSII and PSI are presented in Table 2. The rate of excitation $\mathrm{Exc}_{\mathrm{II}}$ and $\mathrm{Exc}_{\mathrm{I}}$ (in quanta $\cdot \mathrm{ms}^{-1}$ ) at both photosystems is now given by:

$$
\begin{aligned}
\mathrm{Exc}_{\text {II }} & =\sigma_{\text {PSII }} \text { PFD cf } \\
\mathrm{Exc}_{\mathrm{I}} & =\sigma_{\text {PSI }} \text { PFD } \mathrm{cf}
\end{aligned}
$$

where PFD is the photon flux density (in $\mu$ mol quan$\left.\mathrm{ta} \cdot \mathrm{m}^{-2} \cdot \mathrm{s}^{-1}\right)$ and $\mathrm{cf}\left(6.02 \times 10^{14}\right)$ a conversion factor

TABLE 8. The set of ordinary differential equations describ-

\begin{tabular}{|c|c|}
\hline \\
\hline Number & Equation \\
\hline ODE1 & $\mathrm{d} X_{1} / \mathrm{d} t=-\mathrm{qR} 1+\mathrm{qR} 2+\mathrm{qR} 3-\mathrm{qR} 4+\mathrm{qR} 5$ \\
\hline ODE2 & $\mathrm{d} X_{2} / \mathrm{d} t=\mathrm{qR} 4-\mathrm{qR} 9+\mathrm{qR} 10+\mathrm{qR} 11-\mathrm{qR} 5$ \\
\hline ODE3 & $\mathrm{d} X_{3} / \mathrm{d} t=\mathrm{qR} 1-\mathrm{qR} 2-\mathrm{qR} 6+\mathrm{qR} 7+\mathrm{qR} 8$ \\
\hline ODE4 & $\mathrm{d} X_{4} / \mathrm{d} t=\mathrm{qR} 6+\mathrm{qR} 9-\mathrm{qR} 10-\mathrm{qR} 12+\mathrm{qR} 13-\mathrm{qR} 7+\mathrm{qR} 1$ \\
\hline ODE5 & $\mathrm{d} X_{5} / \mathrm{d} t=\mathrm{qR} 15-\mathrm{qR} 17+\mathrm{qR} 18-\mathrm{qR} 16-\mathrm{qR} 14$ \\
\hline ODE6 & $\mathrm{d} X_{6} / \mathrm{d} t=\mathrm{qR} 12-\mathrm{qR} 13-\mathrm{qR} 15+\mathrm{qR} 16-\mathrm{qR} 8$ \\
\hline ODE7 & $\mathrm{d} X_{7} / \mathrm{d} t=\mathrm{qR} 17-\mathrm{qR} 18-\mathrm{qR} 3-\mathrm{qR} 19+\mathrm{qR} 20$ \\
\hline ODE8 & $\mathrm{d} X_{8} / \mathrm{d} t=\mathrm{qR} 19-\mathrm{qR} 11-\mathrm{qR} 20$ \\
\hline ODE9 & $\mathrm{d} X_{9} / \mathrm{d} t=\mathrm{qR} 3+\mathrm{qR} 11-\mathrm{bR} 2-\mathrm{bR} 5+\mathrm{bR} 8$ \\
\hline ODE10 & $\mathrm{d} X_{10} / \mathrm{d} t=-\mathrm{qR} 1-\mathrm{qR} 9+\mathrm{qR} 2+\mathrm{qR} 10+\mathrm{bR} 2+\mathrm{bR} 5-\mathrm{bR} 8$ \\
\hline ODE11 & $\mathrm{d} X_{11} / \mathrm{d} t=\mathrm{bR} 8-\mathrm{bR} 1-\mathrm{bR} 11$ \\
\hline ODE12 & $\mathrm{d} X_{12} / \mathrm{d} t=\mathrm{bR} 1-\mathrm{bR} 2$ \\
\hline ODE13 & $\mathrm{d} X_{13} / \mathrm{d} t=\mathrm{bR} 2-\mathrm{bR} 3$ \\
\hline ODE14 & $\mathrm{d} X_{14} / \mathrm{d} t=\mathrm{bR} 3-\mathrm{bR} 4-\mathrm{bR} 10+\mathrm{bR} 12$ \\
\hline ODE15 & $\mathrm{d} X_{15} / \mathrm{d} t=\mathrm{bR} 4-\mathrm{bR} 5$ \\
\hline ODE16 & $\mathrm{d} X_{16} / \mathrm{d} t=\mathrm{bR} 5-\mathrm{bR} 6$ \\
\hline ODE17 & $\mathrm{d} X_{17} / \mathrm{d} t=\mathrm{bR} 6+\mathrm{bR} 9-\mathrm{bR} 7$ \\
\hline ODE18 & $\mathrm{d} X_{18} / \mathrm{d} t=\mathrm{bR} 7-\mathrm{bR} 8$ \\
\hline ODE19 & $\mathrm{d} X_{19} / \mathrm{d} t=\mathrm{bR} 11-\mathrm{bR} 12$ \\
\hline ODE20 & $\mathrm{d} X_{20} / \mathrm{d} t=\mathrm{bR} 10-\mathrm{bR} 9$ \\
\hline ODE21 & $\mathrm{d} X_{21} / \mathrm{d} t=-\mathrm{R} 3+\mathrm{R} 2 \mathrm{a}+\mathrm{R} 2 \mathrm{~b}+\mathrm{R} 2 \mathrm{c}+\mathrm{R} 2 \mathrm{~d}-\mathrm{bR} 10-\mathrm{bR} 11$ \\
\hline ODE22 & $\mathrm{d} X_{22} / \mathrm{d} t=\mathrm{R} 3-\mathrm{R} 2 \mathrm{a}-\mathrm{R} 2 \mathrm{~b}-\mathrm{R} 2 \mathrm{c}-\mathrm{R} 2 \mathrm{~d}+\mathrm{bR} 9+\mathrm{bR} 12$ \\
\hline ODE23 & $\mathrm{d} X_{23} / \mathrm{d} t=-\mathrm{bR} 1-\mathrm{bR} 4+\mathrm{R} 4$ \\
\hline ODE24 & $\mathrm{d} X_{24} / \mathrm{d} t=\mathrm{bR} 1+\mathrm{bR} 4-\mathrm{R} 4$ \\
\hline ODE25 & $\mathrm{d} X_{25} / \mathrm{d} t=-\mathrm{R} 1 \mathrm{a}+\mathrm{R} 2 \mathrm{a}$ \\
\hline ODE26 & $\mathrm{d} X_{26} / \mathrm{d} t=\mathrm{R} 1 \mathrm{a}-\mathrm{R} 2 \mathrm{a}-\mathrm{R} 1 \mathrm{~b}+\mathrm{R} 2 \mathrm{~b}$ \\
\hline ODE27 & $\mathrm{d} X_{27} / \mathrm{d} t=\mathrm{R} 1 \mathrm{~b}-\mathrm{R} 2 \mathrm{~b}-\mathrm{R} 1 \mathrm{c}+\mathrm{R} 2 \mathrm{c}$ \\
\hline ODE28 & $\mathrm{d} X_{28} / \mathrm{d} t=\mathrm{R} 1 \mathrm{c}-\mathrm{R} 2 \mathrm{c}-\mathrm{R} 1 \mathrm{~d}+\mathrm{R} 2 \mathrm{~d}$ \\
\hline ODE29 & $\mathrm{d} X_{2 \mathrm{~g}} / \mathrm{d} t=\mathrm{R} 1 \mathrm{~d}-\mathrm{R} 2 \mathrm{~d}$ \\
\hline ODE30 & $\mathrm{d} X_{30} / \mathrm{d} t=\mathrm{R} 4-\mathrm{R} 1 \mathrm{a}-\mathrm{R} 1 \mathrm{~b}-\mathrm{R} 1 \mathrm{c}-\mathrm{R} 1 \mathrm{~d}$ \\
\hline ODE31 & $\mathrm{d} X_{31} / \mathrm{d} t=-\mathrm{R} 4+\mathrm{R} 1 \mathrm{a}+\mathrm{R} 1 \mathrm{~b}+\mathrm{R} 1 \mathrm{c}+\mathrm{R} 1 \mathrm{~d}$ \\
\hline
\end{tabular}
ing the electron transport from PSII to ferredoxin. The explicit analytical expressions for the reaction rates are given in Table 7 
to convert dimensions ( $\mu \mathrm{mol}$ to quanta, seconds to milliseconds).

Charge Separation at PSII: Trissl and Lavergne (1994) and Lavergne and Trissl (1995) developed a model for the fluorescence and photochemical yields as a function of the number of open PSII reaction centers (i.e. centers with an oxidized $Q_{\mathrm{A}}$ ). The model takes into account reversible exciton trapping by open and closed PSII reaction centers and exciton exchange between PSII units. The model calculations comprise a random walk treatment where the excitations may adopt different and mutually exclusive states. In our model, we considered eight different states of PSII, which are determined by the redox states of $Q_{A}$ and $Q_{B}$ (Fig. 2). Four states represent closed centers: $Q_{\mathrm{A}}^{-}, \mathrm{Q}_{\mathrm{A}}^{-} \mathrm{Q}_{\mathrm{B}}, \mathrm{Q}_{\mathrm{A}}^{-} \mathrm{Q}_{\mathrm{B}}^{-}, \mathrm{Q}_{\mathrm{A}}^{-} \mathrm{Q}_{\mathrm{B}}^{2-}$, and four states represent open centers: $Q_{A}, Q_{A} Q_{B}$, $\mathrm{Q}_{\mathrm{A}} \mathrm{Q}_{\mathrm{B}}^{-}, \mathrm{Q}_{\mathrm{A}} \mathrm{Q}_{\mathrm{B}}^{2-}$. The original model of Trissl and Lavergne (1994) does not differentiate between eight possible states of PSII. However, the random walk treatment proved to be suitable for calculating the photochemical yield $\left(\Phi_{\mathrm{PSII}, i}\right)$ for every possible open $\mathrm{Q}_{\mathrm{A}} \mathrm{Q}_{\mathrm{B}}$ redox state $i$. After a tedious but straightforward calculation we obtained the simple analytical expression for $\Phi_{\mathrm{PSII}, i}$ :

$$
\Phi_{\mathrm{PSII}, i}=\mathrm{A} \frac{X_{i}}{1+\mathrm{J} \Sigma_{i} X_{i}}
$$

where $X_{\mathrm{i}}$ is the state variable for the open PSII unit in state $i$, and $\Sigma_{\mathrm{i}} X_{\mathrm{i}}$ is the sum of all open states. The parameters J (connectivity) and $\mathrm{A}$ in equation (22) depend on first-order rate constants (Table 6) describing the primary processes in PSII. Finally, multiplying equation (22) by the expression for the rate of photon absorption $\left(\mathrm{Exc}_{\mathrm{II}}\right)$ at PSII, which is given in equation (20) yield the rates of $Q_{\mathrm{A}}$ reduction in every possible open state of PSII. The auxiliaries for calculation of the $Q_{A}$ reduction rates in different PSII states are presented in Table 5.

It is noted here, that our description of $Q_{\mathrm{A}}$ reduction does not involve the S-states of the PSII-bound oxygen-evolving complex. The decision to leave out a description of the S-states is that it would have increased the number of ordinary differential equations (ODEs) 4-fold while not changing the basic behavior of the redox state of the system in response to light. The known small effect of the S-States is a result of the fact that a distribution of the S-states (with different electron transfer rates for each state) equilibrates already after 10 to 20 photochemical events and therefore, can only be observed after a carefully selected experimental set-up. Furthermore, our model is able to include all transient phenomena in a typical Kautsky induction experiment (see results), without invoking an explanation based on S-States.

From PSII to plastoquinol. Within PSII electrons are transported from $Q_{A}$ to $Q_{B}$. Once doubly reduced, the $Q_{B}$ molecule leaves its binding site and now joins the $\mathrm{PQH}_{2}$ pool. The reactions of the electron transfer from PSII to $\mathrm{PQH}_{2}$ are shown in Fig. 2 and the ac- companying reaction rates are presented in the first column of Table 7 . The reactions qR4, qR6, qR15, and qR19 describe charge separation at PSII and subsequent charge stabilization with the transfer of the electron to $Q_{A}$. The reactions $q R 12$, qR13, qR17, and $q R 18$ reflect the electron transfer between $Q_{A}$ and $Q_{B}$. Reactions qR1, qR2, qR9, and qR10 model the binding and unbinding of $Q_{\mathrm{B}}$ to its binding site at the D1 protein. Reactions qR3 and qR11 represent the release of doubly reduced $Q_{\mathrm{B}}$ and concomitant uptake of two protons from the stroma thylakoid to give rise to the formation of $\mathrm{PQH}_{2}$. Reactions qR5, qR7, qR8, qR14, qR16, and qR20 describe the relaxation of the reduced states of the $Q_{A} Q_{B}$ complex in darkness. The electron acceptor for these proposed relaxation pathways is unknown, but must be present in order to allow a complete restoration to a darkadapted state after exposure to light.

From plastoquinol to plastocyanin: Electron transfer from $\mathrm{PQH}_{2}$ to PSI proceeds through the cyt b6/f complex and PC. The cyt b6/f complex consists of the Rieske iron-sulfur center, two cytochromes b6, and one cytochrome $f$. The complex has two quinone binding sites (luminal (p) and stromal (n)) involved in the redox conversions of $\mathrm{PQ}$. By following a sequence of events known as the $\mathrm{Q}$-cycle, two protons are transported from the chloroplast stroma to the thylakoid lumen for every electron flowing through the cyt b6/f complex from $\mathrm{PQH}_{2}$ to PC. The PC shuttles the electron to PSI. The reactions and reaction rates of the Q-cycle pathway are presented in Fig. 3 and in the second column of Table 7 , respectively. The Rieske iron-sulfur center and cytochrome $f$ are treated here as one complex (FeSf), so the internal electron transfer steps are not given separately. Likewise, the electron transfer between the low and high potential cytochromes $b 6\left(b_{p}\right.$ and $b_{n}$, respectively) is presented in one step as electron transfer to $b_{p} b_{n}$. The reactions bR1 to bR3 describe the oxidation of FeSf by oxidized PC and subsequent reduction of FeSf and $b_{p} b_{n}$ by transfer of two electrons from $\mathrm{PQH}_{2}$ at the $Q_{o}$ site with concomitant release of two protons in the lumen. At this stage, the cytochrome b6/f complex has one electron at the stroma side of the $b_{p} b_{n}$ complex. A second turn of the Q-cycle proceeds similarly through reactions bR4 through bR6, now followed by reaction bR7, the reduction of $P Q$ at the $Q_{i}$ side of the complex . The formation of a semiquinone at the $Q_{\mathrm{i}}$ side after reaction bR3 is not shown explicitly.

While known for many years, the exact biochemical pathway for cyclic PSI transfer is still unclear. Here, two possible interactions between $\mathrm{Fd}$ and cytochrome b6/f are given (first, reactions bR 11 and bR 12 and second, reactions bR9 and bR10). Reactions bR11 and bR12 describe the first electron donation from reduced $\mathrm{Fd}$ leading to the reduction of $\mathrm{b}_{\mathrm{p}}$. A second step (bR9 and bR10) leads to a doubly reduced state of $b_{p} b_{n}$, which can then reduce PQ at the stroma side. In this way, cyclic PSI transfer in itself does not lead to the 
release of protons into the lumen directly, but contributes to the formation of a proton gradient $(\Delta \mathrm{pH})$ across the thylakoid membrane due to the uptake of protons from the stroma. Furthermore, this cyclic pathway auto-catalyzes a reduction of the PQ pool without engagement of PSII. As a result, after several turnovers of the cyclic pathway, reactions bR 1 to bR8 (including disposition of protons at the stroma side) can now proceed without PSII action.

From PSI to Fd. The PSI complex is modelled here by the state of the primary electron donor $\mathrm{P}_{700}$ and the FeS acceptor complex $A_{o} A_{1} F_{x} F_{A B}$ (Fig. 4). The FeS designates the entire complex of acceptors: a single chl $a\left(\mathrm{~A}_{\mathrm{o}}\right)$, a phylloquinone $\left(\mathrm{A}_{1}\right)$, the iron-sulfur cluster $\left(\mathrm{F}_{\mathrm{x}}\right)$, and the terminal iron-sulfur acceptors $\left(\mathrm{F}_{\mathrm{AB}}\right)$. The reaction rates for the PSI catalytic cycle are given in the third column of Table 7. Because PSI is a good quencher of excitation energy in its oxidized as well as in its reduced form, the quantum yield of PSI $\left(\Phi_{\text {PSI }}\right)$ is not modelled as a function of antennae characteristics (as is customary for $\Phi_{\mathrm{PSII}, i}$ ). Consequently, $\Phi_{\text {PSI }}$ can be set to 1 , its maximal value, while the effective quantum yield is given by the ratio of reduced and oxidized $\mathrm{P}_{700}$ (Harbinson and Baker 1989). After charge separation at $\mathrm{P}_{700}$, the electron transfer takes place in four steps through the complex (reactions $\mathrm{R} 1 \mathrm{a}$ through $\mathrm{R} 1 \mathrm{~d}$ ) and oxidized $\mathrm{P}_{700}$ itself is reduced by plastocyanin (reaction R4). No difference is made whether a linear or a branched chain exists between the iron-sulfur cluster $F_{x}$ and the terminal iron-sulfur acceptors $\mathrm{F}_{\mathrm{A}} \mathrm{F}_{\mathrm{B}}$. Reoxidation of the complex by $\mathrm{Fd}$ and concomitant movement of the electrons through the complex is given by reactions $\mathrm{R} 2 \mathrm{a}$ through $\mathrm{R} 2 \mathrm{~d}$. Reaction R3 reflects the final reoxidation of reduced Fd due to linear electron transport of the electron transport chain. Reaction R3 in fact combines the kinetic properties of four enzymes, which serve as electron acceptors of $\mathrm{Fd}: \mathrm{Fd}^{-\mathrm{NADP}^{+}}$oxidoreductase (FNR), Fd-nitrite oxidoreductase (FNiR), glutamine-oxoglutarate aminotransferase (GOGAT), Fdthioredoxin oxidoreductase (FTR).

Numerical integration of ordinary differential equations system (ODEs). Based on the reaction rates given in Table 7 , we translated the flow diagrams of reactions chains related to PSII, cyt b6/f, and PSI (Figs. 2-4) into balance equations. In this way, we obtained the explicit form of the ODEs 17, which is presented in Table 8.

The software package Mathematica running under UNIX on a SunBlade 150 workstation has been used for numerically solving the set of model equations. The numerical method used for the simulations was based on the LSODE algorithm that detects whether the system of differential equations is stiff or not and uses the most efficient method for numerical integration. This method is provided by the Mathematica function NDSolve, which for non-stiff systems uses the method of Adams, while for stiff systems uses the method of Gear. Because of its use of the Gear algorithm, NDSolve is well suited to numerical integration of ODEs describing metabolic systems.
The initial values for the state variables of the differential equation in Table 8 are chosen such, that they reflect a dark adapted state. Different stoichiometries of the components of the electron transport chain are easily implemented by setting the initial condition of the appropriate state variable to its desired value. Here, we will adhere to a stoichiometry of unity for all components except the PQ pool (see equation (14)). Of particular importance is the fact, that in the darkadapted state the $\mathrm{PQ}$ (or $\mathrm{Q}_{\mathrm{B}}$ ) bound to its D1 binding site $\left(Q_{A} Q_{B}\right)$ is in equilibrium with the free $P Q$ pool $(\mathrm{qR} 1=\mathrm{qR} 2$, see Fig. 2 and first column of Table 7$)$. The $Q_{A} Q_{B}$ dissociation constant can be expressed in terms of fractions $X_{1}$ and $X_{3}$ of open PSII centres at time $t=0$, and is denoted as

$$
K=\frac{X_{1}(t=0) X_{10}(t=0)}{X_{3}(t=0)}=\frac{k a v}{k v a}
$$

where $X_{10}(t=0)$ is the number of free PQ relative to PSII in equilibrium with $Q_{A} Q_{B}$ in darkness. We denote by $x$ the ratio of the $Q_{\mathrm{A}} Q_{\mathrm{B}}$ dissociation constant and the initial value of $X_{10}$ :

$$
x=\frac{K}{X_{10}(t=0)}
$$

Then, assuming that in the dark the PSII centers adopt only open states with empty or oxidized $Q_{\mathrm{B}}$, i.e.

$$
X_{1}(t=0)+X_{3}(t=0)=1
$$

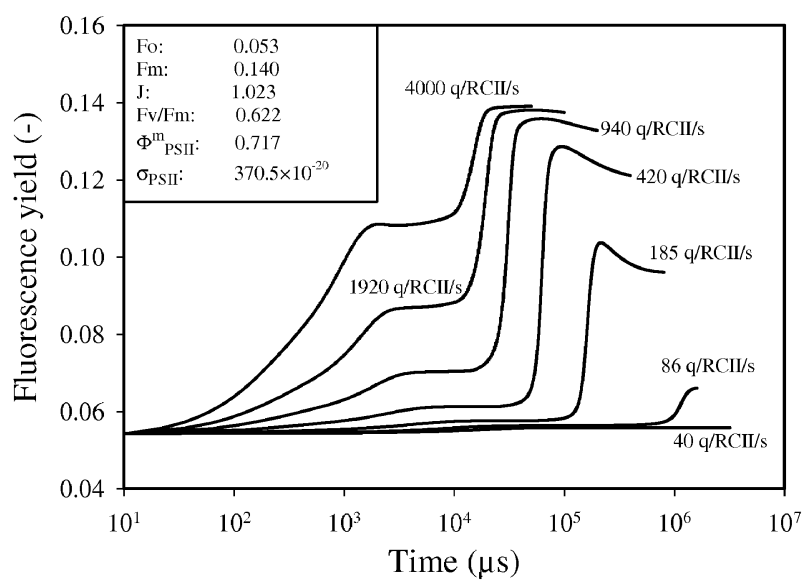

Fig. 5. Example of the model output in terms of fluorescence yield $\left(\Phi_{\mathrm{f}}\right.$, see Table 5$)$ simulating the technique of a fast repetition rate fluorometer, which, in this case, leads to a multiple turnover induction. Flashlets, each of $0.8 \mu$ s duration with an intensity of $27500 \mu \mathrm{mol}$ quanta $\cdot \mathrm{m}^{2} \cdot \mathrm{s}^{-1}$, were applied with varying frequency between $81.97 \mathrm{kHz}$ down to $815 \mathrm{~Hz}$. The resulting excitation pressure in quanta per reaction center and per second $(\mathrm{q} / \mathrm{RCII} / \mathrm{s})$ is indicated next to the traces. Scenario 1 from Table 2 was taken as antenna composition. The inset gives overall characteristics of PSII using this antenna composition: $\sigma_{\mathrm{PSII}}\left(\mathrm{m}^{2}\right)$, optical cross section; $\sigma_{\mathrm{PSII}}^{\mathrm{m}}\left(\mathrm{mol} \mathrm{e}^{-} \cdot \mathrm{mol}^{-1}\right.$ quanta), maximum quantum yield; $\mathrm{J}(-)$, connectivity parameter. $\mathrm{F}_{\mathrm{o}}(-)$ and $\mathrm{F}_{\mathrm{m}}(-)$ denote the minimum value (fluorescence with all centers open, $q=1$ ) and the maximum value of $\Phi_{\mathrm{f}}$ (fluorescence with all centers closed, $q=0)$, respectively; $F_{v}=F_{m}-F_{o}$. 
we obtain the initial values of $X_{1}$ and $X_{3}$ :

$$
X_{1}(t=0)=\frac{x}{x+1}, \quad X_{3}(t=0)=\frac{1}{x+1}
$$

The initial values for all state variables are listed in the third column of Table 3 .
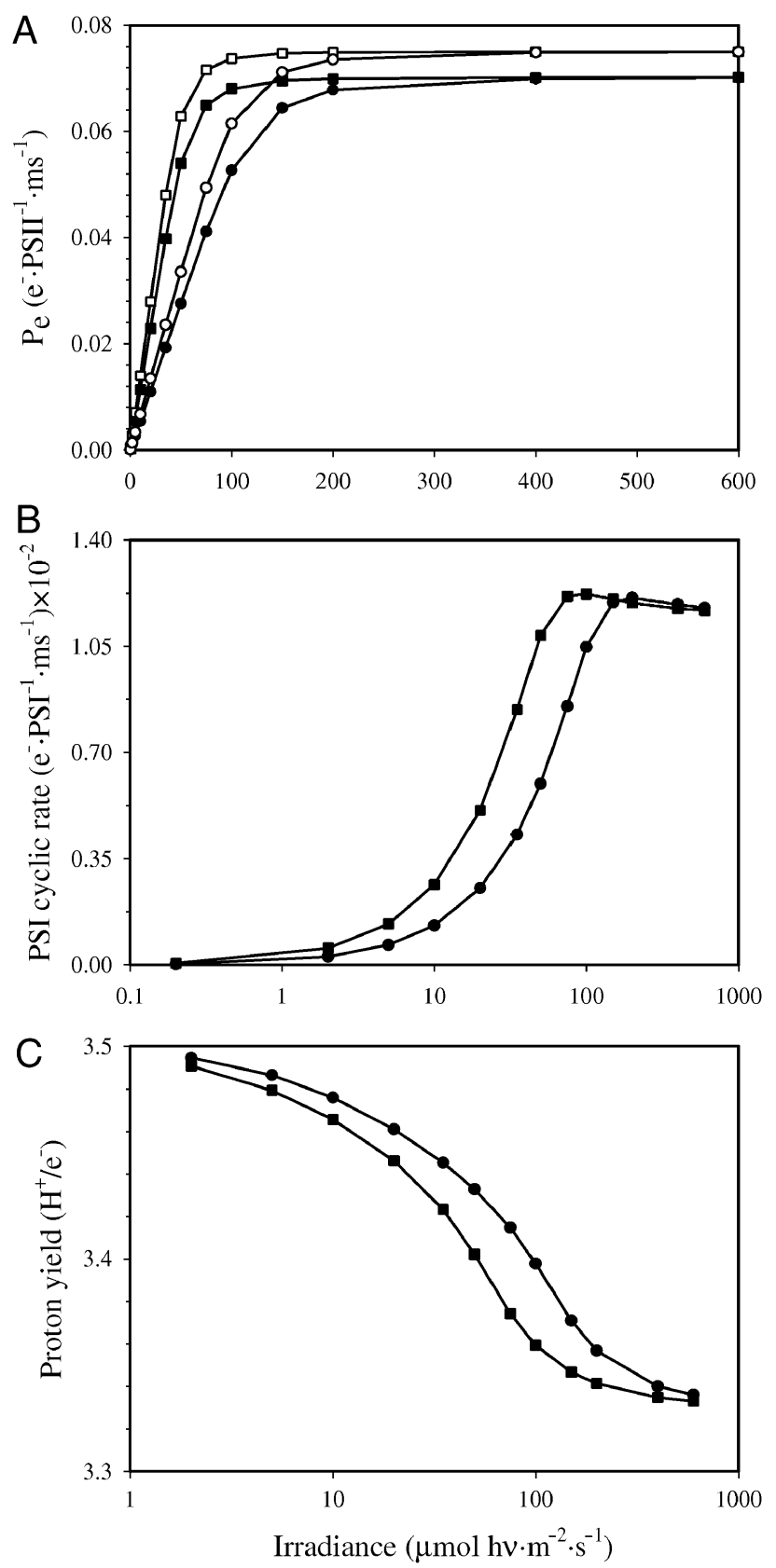

FIG. 6. Photosynthesis (A), PSI cyclic electron transport (B), and $\mathrm{H}^{+} / \mathrm{e}^{-}$ratio $(\mathrm{C})$ as a function of irradiance. The rate constant of terminal $\mathrm{Fd}$ reoxidation was $0.12 \mathrm{~ms}^{-1}$, and the rate constant for cyclic PSI electron transfer was $0.03 \mathrm{~ms}^{-1}$ (closed symbols), or 0 (open symbols). Antennae scenarios 2 (rectangles) and 8 (circles) were simulated (see Table 2 ). For antenna scenario $2, \sigma_{\mathrm{PSII}}$ and $\sigma_{\mathrm{PSI}}$ are $3.386 \times 10^{-18}$ and $2.331 \times 10^{-18} \mathrm{~m}^{2}$, respectively; for antenna scenario 8 , the cross-sections for PSII and PSI are $1.445 \times 10^{-18}$ and $1.123 \times 10^{-18} \mathrm{~m}^{2}$, respectively.

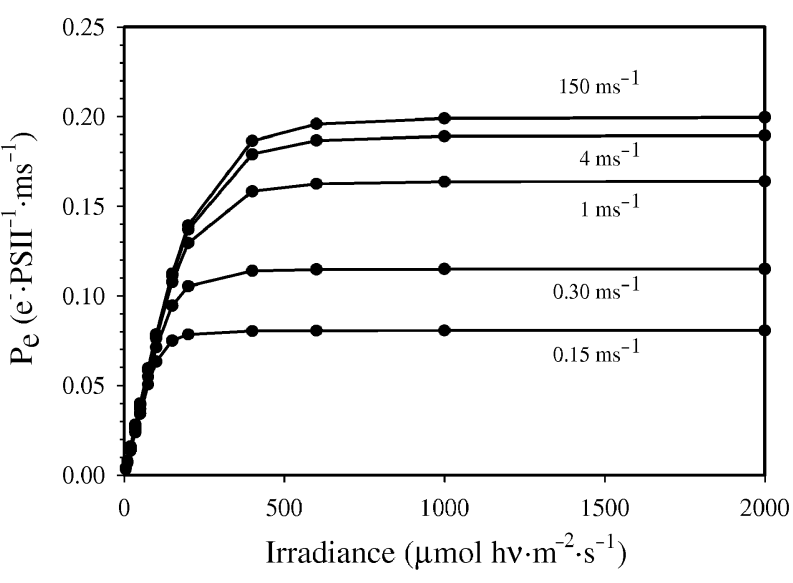

FIG. 7. Photosynthesis as a function of irradiance. The simulations are based on antenna scenario 6 (see Table 2); the value for the rate constant of Fd reoxidation (R3, third column of Table 7) was increased from 0.15 to $150 \mathrm{~ms}^{-1}$ and are indicated in the figure.

\section{RESULTS}

Numerical simulation of primary photosynthetic processes. There is no limit on the diversity of photosynthesis-related phenomena that can be simulated with the proposed model, ranging from fluorescence experiments with a time resolution of several hundreds of nanoseconds, to primary production rates on time scales of hours. One example of how the system simulates a fast photochemical event is shown in Fig. 5. With the availability of highly sophisticated fluorometers, such as the fast repetition rate (FRR) fluorometer, fluorescence measurements using flexible measuring protocols can now routinely be carried out. The FRR technique allows measurements of single and multiple turnover induction curves, fast consecutive inductions, decay curves, and simple pulsed saturation pulses against a background of any chosen actinic irradiance level. By combining one or more of such experimental techniques, the experimental data contain sufficient information to infer all relevant parameter values that together characterize primary photosynthesis. In this work we do not intend to calculate the precise values of the input parameters of the model by fitting experimental data with theoretical curves. However, by using literature data for the rate constants it can be seen that, generally, the integration of the model equations gives typical flourescence induction curves. Figure 5 shows the simulation of the FRR experiment shown in Fig. 7 of Kolber et al. (1998). Here, a sequence of $0.8 \mu$ s short light flashes at varying frequency was used to induce multiple turnovers of PSII. The overall response is influenced by processes including the entire electron transport chain as well as by reactions related to carbon fixation. The transients that occur on the way to the maximum value are related to intrinsic PSII properties as well as electron transfer steps up to Fd. The decrease in fluorescence after reaching a maximal pla- 
teau is caused by the initiation of carbon fixation. Data such as shown in Kolber et al. (1998) and simulated in Fig. 5, where one sample is subjected to different treatments without altering the sample, are well suited for determining the best choice of the essential model parameters by applying a fitting procedure, but this will be the objective of another paper.

Photosynthesis and cyclic PSI transfer: Running the model over a range of light intensities generates a typical $\mathrm{P} / \mathrm{E}$ curve, with photosynthetic rate $\mathrm{P}_{\mathrm{e}}$ $\left(\mathrm{e}^{-} \cdot \mathrm{PSII}^{-1} \cdot \mathrm{ms}^{-1}\right)$. The $\mathrm{P} / \mathrm{E}$ curves are shown in Fig. 6 for two different antennae scenarios (Table 2), both with and without cyclic electron transfer around PSI. The presence of cyclic electron transfer causes a decrease in the maximum photosynthetic rate, whereas a larger antenna size increases the slope of the photosynthetic response at light limiting conditions (Fig. 6A). Cyclic electron transport (the sum of reactions bR 10 and bR 11 , see second column of Table 7) increases in a similar, yet different dependence to irradiance as compared with linear electron transfer (Fig. 6B). The maximum rate of cyclic electron transport does not coincide with the maximum rate of linear electron transport, but reaches a maximum before linear transport saturates. At higher light intensities, cyclic transport decreases. Similar to linear transfer, the absolute rate of cyclic electron transport is larger with a larger antenna size. During linear electron transfer a transport of protons across the thylakoid membrane occurs at PSII during water splitting with a stoichiometry of $1 \mathrm{H}^{+} / \mathrm{e}^{-}$, and during the reoxidation of plastoquinol at the cytochrome b6/f complex (with an active Q-cycle as in our model) with a stoichiometry of $2 \mathrm{H}^{+} / \mathrm{e}^{-}$(reactions bR3 and bR6, see second column of Table 7 and Fig. 3). Cyclic electron transfer (reactions bR 10 and bR 11 , see second column of Table 7) increases the $\mathrm{H}^{+} / \mathrm{e}^{-}$ratio at the cyt $b 6 / f$ site beyond the value of 3 . Because ATP is generated at a ratio 1 ATP per 3 or $4 \mathrm{H}^{+}$(Mills 1996), the rate of ATP synthesis at a given rate of photochemistry is directly proportional to the $\mathrm{H}^{+} / \mathrm{e}^{-}$ratio. The $\mathrm{H}^{+} / \mathrm{e}^{-}$ratio is maximal at limiting irradiance and decreases with increasing irradiance (Fig. 6C). The proton yield is not related to the antenna size of PSII relative to PSI, but increases with smaller antenna sizes. This characteristic has interesting consequences for overall cell growth, which will be discussed later.

The curvature and plateau value of $\mathrm{P} / \mathrm{E}$ curves as shown in Fig. 6A are systemic properties of the electron transport system and are not the result of a limited capacity to consume electrons in upstream metabolic reactions (these processes are collectively represented by the rate constant kterm, see reaction R3, third column of Table 7). With the set of rate constants given in Tables 4 and $5, \mathrm{P}_{\mathrm{e}}$ saturates at a value of $0.2 \mathrm{e}^{-} \cdot \mathrm{PSII}^{-1} \cdot \mathrm{ms}^{-1}$ (which is the maximal rate for completely uncoupled photosynthesis) as the terminal rate of reoxidation of $\mathrm{Fd}$ approaches infinity (Fig. 7).
The conversion of $\mathrm{P}_{\mathrm{e}}$ into the chl-specific photosynthesis rate $\mathrm{P}_{\mathrm{B}}\left(\mathrm{g} \mathrm{C} \cdot \mathrm{g}^{-1} \operatorname{chl} a \cdot \mathrm{h}^{-1}\right)$ only depends on $\gamma_{x}$ and the total number of chl $a$ relative to PSII:

$$
\mathrm{P}_{\mathrm{B}}=\frac{\mathrm{P}_{\mathrm{e}}}{\left(\mathrm{N}_{a \mathrm{II}}+\mathrm{N}_{a \mathrm{I}}\right) \gamma_{x}} \frac{3.6 \times 10^{6} \mathrm{~ms}}{\mathrm{~h}} \frac{12 \mathrm{gC}}{\operatorname{molC}} \frac{\mathrm{mol} \mathrm{chl} a}{893 \mathrm{gchl} a}
$$

Based on the $\mathrm{P}_{\mathrm{e}}$ value and on the quantum yield of PSII, we can estimate the turnover time for the transfer of one electron from water to a terminal acceptor. The quantum yield of PSII ( $\left.\Phi_{\mathrm{PSII}}\right)$ is evaluated by using the result of Lavergne and Trissl (1995), which consists in an analytical expression for $\Phi_{\mathrm{PSII}}$ as a function of the overall fraction $\left(\mathrm{q}=\Sigma_{i} X_{i}\right)$ of open PSII units. This function can be recovered from equation (22) by the sum of the individual contributions $\Phi_{\mathrm{PSII}, i}$ of all open PSII states $i$ :

$$
\Phi_{\mathrm{PSII}}=\sum_{i} \Phi_{\mathrm{PSII}, i}=\mathrm{A} \frac{\mathrm{q}}{1+\mathrm{Jq}}=\Phi_{\mathrm{PSII}}^{\mathrm{m}} \frac{(1+\mathrm{J}) \mathrm{q}}{1+\mathrm{Jq}}
$$

where

$$
\Phi_{\mathrm{PSII}}^{\mathrm{m}}=\frac{\mathrm{A}}{1+\mathrm{J}}
$$

is the maximum quantum yield of PSII at $q=1$. The maximum uncoupled $\mathrm{P}_{\mathrm{e}}$ value corresponds to a $\mathrm{P}_{\mathrm{B}}$ of about $11.5 \mathrm{~g} \mathrm{C} \cdot \mathrm{g}^{-1} \mathrm{chl} a \cdot \mathrm{h}^{-1}$. Then, the minimum turnover time ( $\tau$, in $\mathrm{ms}$ ) required to transfer one electron from water to a terminal acceptor is equal to the ratio of $\Phi_{\mathrm{PSII}}^{\mathrm{m}}$ and $\mathrm{P}_{\mathrm{e}}$. The lowest value for $\tau$ exists, when PSII has the largest antenna size (scenario 1, Table 2). Using the uncoupled value for $P_{e}, \tau$ equals $3.6 \mathrm{~ms}$. For the parameter values given in this paper, $3.6 \mathrm{~ms}$ is minimum time needed to proceed one electron through the electron transport chain. If cells are grown under conditions, which maximize the consumption of electrons, $\tau$ should approximate $3.6 \mathrm{~ms}$, which has indeed been measured $(\tau=3.3 \mathrm{~ms}$, Sukenik et al. 1987).

Photosynthetic parameters derived from the model. The rate of photosynthesis $\mathrm{P}_{\mathrm{e}}$ is numerically equal to reaction R3 in the third column of Table 7. However, $\mathrm{P}_{\mathrm{e}}$ is also equal to:

$$
\mathrm{P}_{\mathrm{e}}=\Phi_{\text {PSII }} \sigma_{\text {PSII }} \text { PFDcf }
$$

As the irradiance approaches 0 , the change in $\mathrm{P}_{\mathrm{e}}$ relative to the change in PFD equals $\alpha_{e}$, which is given by:

$$
\alpha_{\mathrm{e}}=\operatorname{Lim}_{\mathrm{PFD} \rightarrow 0} \frac{d \mathrm{P}_{\mathrm{e}}}{d \mathrm{PFD} \mathrm{cf}}=\operatorname{Lim}_{\mathrm{PFD} \rightarrow 0} \Phi_{\mathrm{PSII}} \sigma_{\mathrm{PSII}}
$$

or, after substituting equation (28) in equation (31):

$$
\alpha_{\mathrm{e}}=\operatorname{Lim}_{\mathrm{PFD} \rightarrow 0} \Phi_{\mathrm{PSII}}^{\mathrm{m}} \sigma_{\mathrm{PSII}} \frac{(1+\mathrm{J}) \mathrm{q}}{1+\mathrm{Jq}}
$$

where $q$ is the sum of $Q_{A}, Q_{A} Q_{B}, Q_{A} Q_{B}^{-}$and $Q_{A} Q_{B}^{2-}$, each a function of PFD.

When the system of differential equations from Table 8 was solved at steady state and the solution for $\mathrm{q}$ (which is an extremely large expression and not shown 


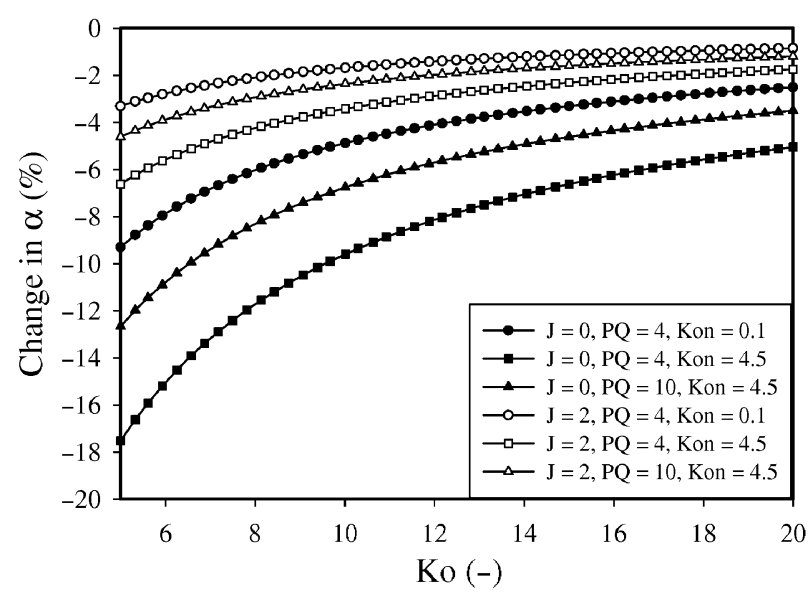

FIG. 8. The definition of $\alpha_{\mathrm{e}}$ becomes dependent on connectivity of the antennae $(\mathrm{J})$, the amount of oxidized $\mathrm{PQ}$ and some rate constants from Table 4 ( $k a v, k v a, k a b O, k b a O)$, if the electron transport chain does not reoxidize completely during dark adaptation (see equation (34)). The percentile change in $\alpha_{\mathrm{e}}$ is shown here relative to the trivial solution (equation (33)) as a function of the equilibrium constant $\mathrm{Ko}(\mathrm{Ko}=k a b O / k b a O)$ for various combinations of $\mathrm{J}$, the total $\mathrm{PQ}$ pool size and the equilibrium constant Kon $($ Kon $=k a v / k v a)$.

here) was substituted in equation (32), a trivial solution for $\alpha_{\mathrm{e}}$ was found:

$$
\alpha_{\mathrm{e}}=\Phi_{\mathrm{PSII}}^{\mathrm{m}} \sigma_{\mathrm{PSII}}
$$

where $\alpha_{\mathrm{e}}$ has dimensions of $\left(\mathrm{mol} \mathrm{e}^{-} \cdot \mathrm{PSII}^{-1} \cdot \mathrm{ms}^{-1}\right)$ (mol quanta $\left.\cdot \mathrm{m}^{-2} \cdot \mathrm{ms}^{-1}\right)^{-1}$ which reduces to mol $\mathrm{e}^{-}$. $\mathrm{m}^{2} \cdot \mathrm{mol}^{-1}$ quanta $\cdot \mathrm{PSII}^{-1}$. This solution is trivial, because all reduced components relax to their oxidized state in darkness (and hence, the sum of all $Q_{\mathrm{A}}$ and $\mathrm{Q}_{\mathrm{A}} \mathrm{Q}_{\mathrm{B}}$ states becomes 1) due to back-reactions $\mathrm{qR}$ 5, qR7, qR8, qR14, qR16 and qR20. There are several occasions, however, where the contribution of these back-reactions could become negligible: the dark adaptation time before the measurement of $\alpha$ or $\Phi_{\mathrm{PSII}}$ is short relative to the timescale of the back-reactions; damage to the $\mathrm{D} 1$ protein (which is the binding site for $Q_{B}$ ), which is believed to occur after chronic high-light or UVB exposure (Marshall et al. 2000), could deteriorate the relaxation of $\mathrm{Q}_{\mathrm{B}}^{-}$or $\mathrm{Q}_{\mathrm{B}}^{2-}$; interference of cellular metabolism on the redox state of PQ (Quigg et al. 2003) and in consequence, a sustained reduced state the $Q_{A} Q_{B}$ complex in darkness.

With a negligible contribution of the back-reactions, equation (32) results in a form, which is different from the trivial solution of equation (33):

$\alpha_{\mathrm{e}}=\Phi_{\mathrm{PSII}}^{\mathrm{m}} \sigma_{\mathrm{PSII}} \frac{2(1+\mathrm{J}) k v a k a b O \mathrm{PQ}}{k b a O k a v+k v a(k b a O+2 k a b O(1+\mathrm{J})) \mathrm{PQ}}$

In order to estimate the sensitivity of the rate constants on $\alpha_{\mathrm{e}}$, we introduced the equilibrium constants Kon $=$ $k a v / k v a$ and $\mathrm{Ko}=k a b O / k b a O$ in equation (34) and calculated the percentile change in $\alpha_{\mathrm{e}}$ as a function of $\mathrm{J}$, Kon, Ko and PQ (Fig. 8) from equation:

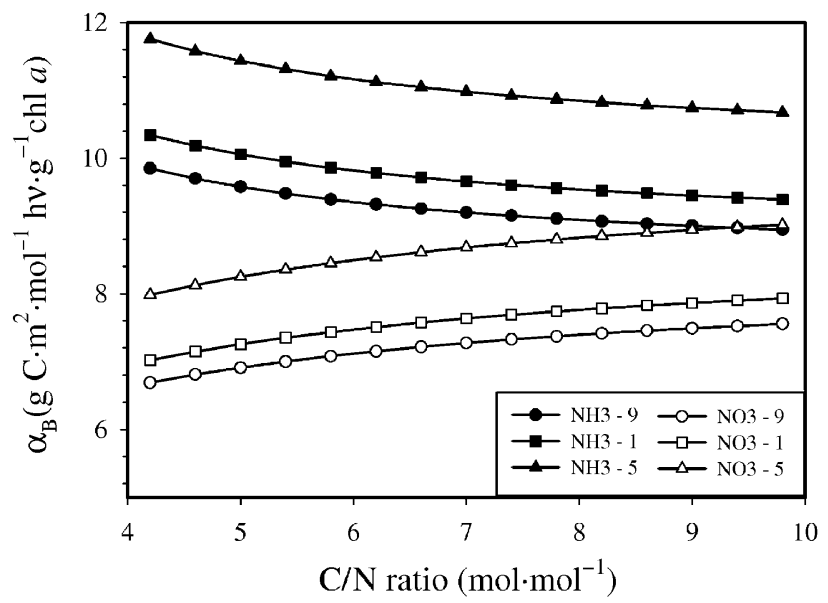

FIG. 9. The relation between $\alpha_{\mathrm{B}}$ and the $\mathrm{C} / \mathrm{N}$ ratio of the biomass. In case nitrate is the nitrogen source, $\alpha_{\mathrm{B}}$ increases with increasing $\mathrm{C} / \mathrm{N}$ ratio (open symbols), whereas it decreases when ammonium is the nitrogen source (closed symbols). The calculations were made for different antenna compositions (see Table 2): scenario 1 (squares), scenario 5 (triangles) and scenario 9 (circles).

$$
\alpha_{\mathrm{e}}=\Phi_{\mathrm{PSII}}^{\mathrm{m}} \sigma_{\mathrm{PSII}} \frac{2(1+\mathrm{J}) \mathrm{Ko} \mathrm{PQ}}{\mathrm{Kon}+(1+2(1+\mathrm{J}) \mathrm{Ko}) \mathrm{PQ}}
$$

As shown, $\alpha_{\mathrm{e}}$ values become reduced by $4 \%-18 \%$, the impact is stronger with low values for Ko, J, and PQ and with high values for Kon.

The conversion of $\alpha_{\mathrm{e}}$ to the chl-specific value $\left(\alpha_{\mathrm{B}}\right.$, as $\left(\mathrm{g} \mathrm{C} \cdot \mathrm{g}^{-1} \operatorname{chl} a \cdot \mathrm{h}^{-1}\right)\left(\mathrm{mol} \text { quanta } \cdot \mathrm{m}^{-2} \cdot \mathrm{h}^{-1}\right)^{-1}$ which reduces to $\mathrm{g} \mathrm{C} \cdot \mathrm{m}^{2} \cdot \mathrm{mol}^{-1}$ quanta $\cdot \mathrm{g}^{-1} \mathrm{chl} a$ ) proceeds in analogy to the conversion of $\mathrm{P}_{\mathrm{e}}$ into $\mathrm{P}_{\mathrm{B}}$ and is given by:

$\alpha_{\mathrm{B}}=\frac{\alpha_{\mathrm{e}}}{\left(\mathrm{N}_{a \mathrm{II}}+\mathrm{N}_{a \mathrm{I}}\right) \gamma_{x}} \frac{6.02 \times 10^{23} \operatorname{chl} a}{\operatorname{mol} \operatorname{chl} a} \frac{12 \mathrm{~g} C}{\operatorname{mol} C} \frac{\mathrm{mol} \operatorname{chl} a}{893 \mathrm{~g} \mathrm{chl} a}$

When $\alpha$ is derived from first principles as is shown above for $\alpha_{e}$, its value only depends on intrinsic rate constants and optical components of PSII. Its conversion to the chl-specific value $\left(\alpha_{\mathrm{B}}\right)$, as is usually reported in literature and given by equation (36), shows that $\alpha$ now also becomes dependent on the elemental composition of the biomass and the nitrogen source (through $\gamma_{x}$ ). Furthermore, $\alpha_{B}$, as a consequence of being expressed on the total amount of $\operatorname{chl} a$, becomes dependent on a pigment that is not exclusively assigned to PSII, but also to PSI. The overview of the elemental composition of various phytoplankton species (Table 1) shows that the fraction of $\mathrm{H}, \mathrm{O}$, and $\mathrm{N}$ (expressed as the ratio of standard deviation and average, in percent) varies by $0.7 \%, 8 \%$, and $23 \%$, respectively. In order to examine the effect of $\gamma_{x}$ on $\alpha_{\mathrm{B}}$, we assumed a hypothetical cell whose elemental composition for $\mathrm{C}, \mathrm{H}$, and $\mathrm{O}$ reflects the average value of all species, and we varied the molar ratio of $\mathrm{N}$ over a 


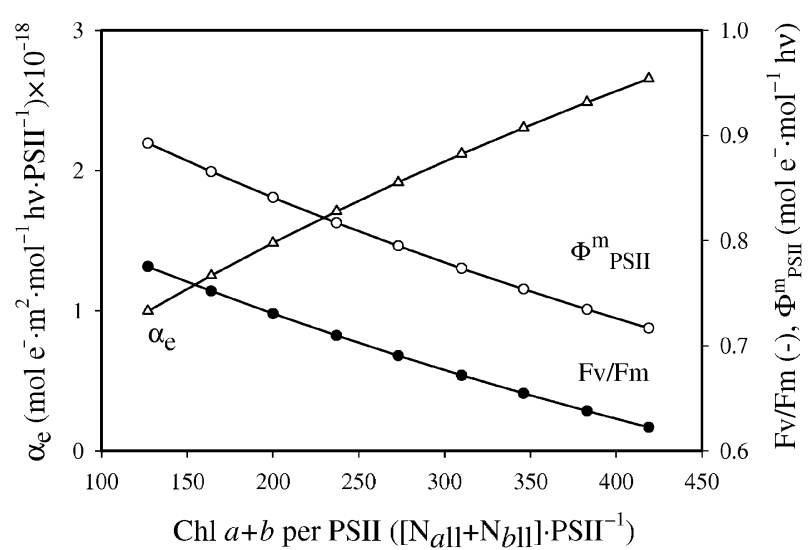

FIG. 10. Owing to an increase in the antennae size (e.g., by light limitation), the intrinsic PSII maximum quantum yield $\left(\Phi_{\mathrm{PSII}}^{\mathrm{m}}\right)$ as well as $\mathrm{F}_{\mathrm{v}} / \mathrm{F}_{\mathrm{m}}$ will decrease as energy losses have a larger impact with a large antennae size. The larger antenna size over-compensate energetic losses, and therefore, $\alpha_{\mathrm{e}}$ increases with antenna size.

range from its minimum to its maximum value from Table 1. In effect, values for $\gamma_{x}$ then range from 4.4 to 9.2 when calculated for both nitrate and ammonium as nitrogen source. When nitrate is the N-source, $\alpha_{\mathrm{B}}$ increases with increasing $\mathrm{C} / \mathrm{N}$ ratios of the phytoplankton biomass. In contrast, $\alpha_{\mathrm{B}}$ decreases with increasing $\mathrm{C} / \mathrm{N}$ ratio when ammonium is the $\mathrm{N}$-source. Species grown on ammonium show higher $\alpha_{B}$ values in general (Fig. 9).

Both the antennae sizes of PSII and PSI increase with more severe light limitation. With a larger antennae, the impact of energy losses from the pigment bed in PSII increases, and $\Phi_{\mathrm{PSII}}^{\mathrm{m}}$ as well as the fluorescence parameter $\mathrm{F}_{\mathrm{v}} / \mathrm{F}_{\mathrm{m}}$ will decrease (Fig. 10). The increase in the optical cross sections $\sigma_{\text {PSII }}$, however, over-compensates the losses, and $\alpha_{e}$ still increases with increas-

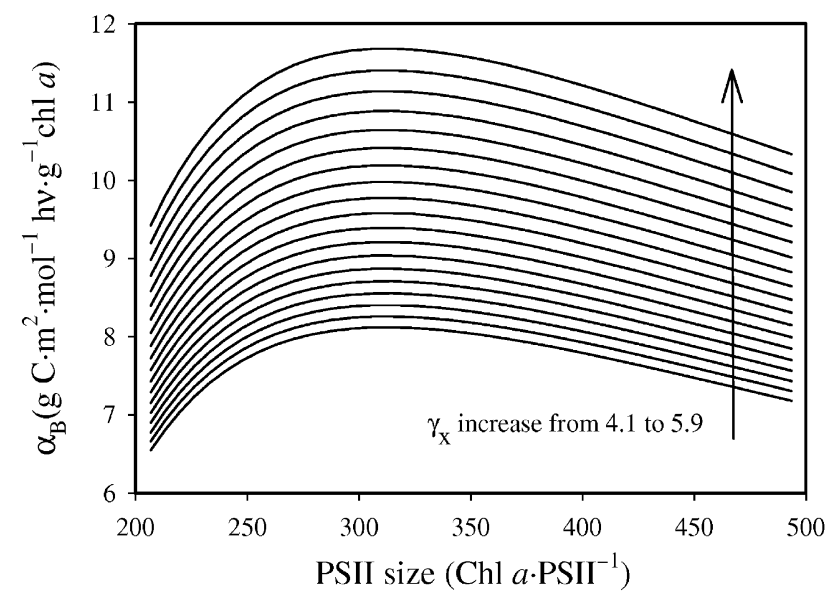

FIG. 11. The relation between $\alpha_{\mathrm{B}}$ and the "antenna size" of PSII (expressed as the total number of chl $a$ per PSII), shown for increasing values for $\gamma_{x} . \alpha_{B}$ initially increases with antennae size, however, then decreases with a further enlargement of the numerical ratio of chl $a$ per PSII. The shape of the curve is slightly more pronounced with increasing values for $\gamma_{x}$. ing antenna size. Because $\alpha_{B}$ is expressed on the basis of all chl $a$, it only increases with antennae size up to some point, after which further decreases with increasing light limitation, the effect being slightly more pronounced with increasing $\gamma_{x}$ (Fig. 11).

Derivation of growth rate. In this paper, we expressed $\gamma_{x}$ quantitatively relative to one mole of $\mathrm{C}$ biomass. Thus, $\gamma_{x}$ equals the moles of electrons that are needed to make one mole of $\mathrm{C}$ biomass. In analogy, it is possible to express the rate of photosynthesis relative to one mole of $\mathrm{C}$ biomass $\left(\mathrm{P}_{\mathrm{e}, \mathrm{c}}\right)$ :

$$
\mathrm{P}_{\mathrm{e}, \mathrm{c}}=\frac{\mathrm{P}_{\mathrm{e}}}{\theta\left(\mathrm{N}_{a \mathrm{II}}+\mathrm{N}_{a \mathrm{I}}\right)} \frac{12 \mathrm{~g} \mathrm{C}}{\mathrm{mol} \mathrm{C}} \frac{\mathrm{mol} \mathrm{chl} a}{893 \mathrm{~g} \mathrm{chl} a}
$$

where $\theta$ is the carbon to $\operatorname{chl} a$ ratio $\left(\mathrm{g} \mathrm{C} \mathrm{g}^{-1} \mathrm{chl} a\right)$. As indicated by Bannister (1979), it is possible to exchange $\theta$ by an appropriate combination of $\omega$ $\left(\mathrm{g} \mathrm{C}^{\mathrm{C}}\right.$ cell $\left.^{-1}\right), \mathrm{n}$ (number of PSII cell $\left.{ }^{-1}\right)$, and $\mathrm{s}$ $\left(\left(\mathrm{N}_{a \mathrm{II}}+\mathrm{N}_{a \mathrm{I}}\right)\right.$ PSII $\left.^{-1}\right)$, since:

$$
\theta=\frac{\omega N_{\mathrm{av}}}{\mathrm{n} \mathrm{s} \mathrm{Mw} \mathrm{chl} a}
$$

where $N_{\text {av }}$ is Avogadro's number $\left(6.02 \times 10^{23}\right)$ and $\mathrm{Mw} \operatorname{chl} a$ is the molecular weight of $\operatorname{chl} a$.

The quotient of the quantity $\gamma_{x}$ and the flux $\mathrm{P}_{\mathrm{e}, \mathrm{c}}$ equals the time interval $\left(\mathrm{T}_{\mathrm{d}}\right)$ to double the biomass:

$$
\begin{aligned}
\mathrm{T}_{\mathrm{d}} & =\frac{\gamma_{x}}{\mathrm{P}_{\mathrm{e}, \mathrm{c}}}=\frac{\gamma_{x} \theta}{\mathrm{P}_{\mathrm{e}}}\left(\mathrm{N}_{\mathrm{aII}}+\mathrm{N}_{\mathrm{aI}}\right) \frac{\text { day }}{8.64 \times 10^{7} \mathrm{~ms}} \\
& \times \frac{\mathrm{molC}}{12 \mathrm{~g} \mathrm{C}} \frac{893 \mathrm{~g} \mathrm{chl} a}{\operatorname{molchl} a}
\end{aligned}
$$

Using the well-known relation between growth rate $(\mu)$ and $T_{d}$ :

$$
\mu=\frac{1}{\mathrm{~T}_{\mathrm{d}}} \ln (2)
$$

we now arrive at a final expression for the growth rate as a function of photosynthetic electron flow:

$$
\begin{aligned}
\mu & =\ln (2) \frac{\mathrm{P}_{\mathrm{e}}}{\gamma_{x} \theta\left(\mathrm{N}_{a \mathrm{II}}+\mathrm{N}_{a \mathrm{I}}\right)} \frac{8.64 \times 10^{7} \mathrm{~ms}}{\text { day }} \\
& \times \frac{12 \mathrm{~g} \mathrm{C}}{\operatorname{mol~C}} \frac{\mathrm{molchl} a}{893 \mathrm{gchl} a}
\end{aligned}
$$

It is noted here, that the growth rate $\mu$ represents the gross productions rate because metabolic losses like respiration and excretion are not taken into account in equations (39)-(41).

\section{DISCUSSION}

The presented model allows a detailed analysis of experimental data that describe photochemical effects. One example of a rather complex fluorescence induction phenomenon that matches published data (Kolber et al. 1998) rather well, without altering any of the given rate constants as given in Tables 4 and 5 , is shown in Fig. 5. The agreement demonstrates the potential of the model to further interpret fluorescence measurements. 
Obviously, the description of the antenna systems should be adapted to accommodate experiments where cyanobacteria or chromophytes are concerned. Extensions to the model are easily incorporated using the presented set of equations. For example, state transitions are easily implemented by explicitly formulating the activity of a kinase and phosphatase, which will dynamically alter the antenna size of PSII and PSI as a function of the redox state of the PQ pool or the cytochrome b6/f complex (Allen 1995). Likewise, by including xanthophylls into the antenna system and adding reversible rate reactions that describe the conversion of energy-transferring to energy-dissipating molecules (Schubert et al. 1994), one would extend the applicability of the model to investigate effects of non-photochemical quenching of photosynthesis as well. Here, we focus on effects that are valid and independent of further refinements of the model.

The generally accepted view that an increase in $\alpha_{B}$ reflects an adaptive strategy to growth under light-limited conditions (which holds true for $\alpha_{\mathrm{e}}$ which is photochemically defined) can now be refined. First, for any given antenna size (or level of light limitation), $\alpha_{B}$ increases with nitrate as $\mathrm{N}$-source, or decreases with ammonium as $\mathrm{N}$-source, if the carbon to nitrogen ratio of the phytoplankton increases. Such behavior of $\alpha_{B}$ might be detected in field studies, when data are compared with samples that have various $\mathrm{C} / \mathrm{N}$ ratios originating from areas where new primary production ( $\mathrm{N}$-source is nitrate) is dominant with data from areas where regenerative production dominates (and hence, with ammonium as $\mathrm{N}$-source). Second, if environmental conditions impose a decrease in available light, then $\alpha_{B}$ will only increase with antenna size up to a maximum, after which $\alpha_{\mathrm{B}}$ will start to decrease again. This effect is slightly more pronounced, and $\alpha_{B}$ values tend to be higher, with phytoplankton species that have a higher $\gamma_{x}$ value. Lastly, prior to acquiring data to derive $\alpha_{\mathrm{B}}$, care should be taken to allow an adequate pre-treatment of the samples, which allows a relaxation of the intersystem electron carriers. This pre-treatment might be a dark adaptation for undamaged cells, or might better be exposure to low light prior to dark incubation, in case the D1 protein is damaged, in order to allow for sufficient repair reactions to take place.

The rate of cyclic electron transfer around PSI increases with increasing irradiance to a temporary maximum, and the increase is larger with a larger PSI antenna size or smaller PSII antenna size relative to PSI. The maximal cyclic electron transport rate, however, saturates before the rate of linear electron transport reaches its maximal value. Owing to the differential demand for ATP and NADPH of various biochemical pathways, it is the ratio between these two photochemically generated compounds that exerts influence on the activity of biochemical pathways. The ATP/NADPH ratio is proportionally dependent on the ratio of the rate of $\mathrm{H}^{+}$transport into the luminal side of the chloroplast relative to the rate of electron trans- port. The $\mathrm{H}^{+} / \mathrm{e}^{-}$ratio is maximal at extreme low light levels, and decreases with increasing irradiance. In contrast to the rate of cyclic electron transport, the $\mathrm{H}^{+} / \mathrm{e}^{-}$ratio is less with a small PSI and/or PSII antenna size, even when the antenna size of PSII relative to PSI decreases. This result explains two long-known phenomena (Morris 1981): first, protein synthesis saturates at lower light intensities than carbohydrate synthesis, simply because protein synthesis requires more ATP. Synthesis of ATP is favored by a higher $\mathrm{H}^{+} / \mathrm{e}^{-}$ ratio, which occurs at low light intensities. Second, the observation that short-term photosynthetic rates always exceed the steady-state rates at the growth irradiance from which the samples were taken might also be explained using the behavior of $\mathrm{H}^{+} / \mathrm{e}^{-}$from Fig. 6C, with an emphasis on the fact that a smaller antenna size causes a higher $\mathrm{H}^{+} / \mathrm{e}^{-}$ratio: for any species growing at its maximal growth rate, antenna sizes are small, and the overall metabolism is fine-tuned to the available flux of ATP and NADPH. During the measurement of the short-term $\mathrm{P} / \mathrm{E}$ response curve, the sample is subjected to irradiances which are less than the growth irradiance. At that moment, the rate of ATP synthesis increases relative to the rate of NADPH synthesis, which will allow for an additional nutrient uptake (especially nitrate) and/or stimulate protein synthesis (directly, or through conversion of carbohydrate skeletons to protein). Subsequently, carbon fixation can now take place at an enhanced rate relative to the rate that would have been possible if the cells were grown at lower light levels. The lower the irradiance the cells were grown at, and adapted to, the less pronounced this enhancement effect will be.

Theoretically, the model as presented here could describe photosynthesis of any particular species purely based on photochemical reactions. Such an application of the model seems rather impractical, because it would require a data set describing the pigment-protein structure of PSII and PSI, the molar ratios of all electron carriers, rate constants of PSII and all electron transfer steps, and $\gamma_{x}$. Nevertheless, the required data set can be acquired by combination of fluorescence measurements, biochemical analysis of the pigmentprotein complexes and elemental analysis of a species (alternatively, a very accurate steady-state determination of $\mathrm{AQ}$ would suffice). Growth can only be predicted if at least three variables of $n, s, \omega$ or $\theta$ are known in addition. Running the model for all antenna scenarios (Table 2) and $\gamma_{x}$ values (Table 1 ), and varying the final reoxidation rate of $\mathrm{Fd}$ and cyclic electron transfer between $0.06-0.15$ and $0-0.06 \mathrm{~m} / \mathrm{s}$, respectively, yields $\mathrm{P}_{\mathrm{B}}$ values between $0.6-4.9 \mathrm{~g} \mathrm{C} \cdot \mathrm{g}^{-1} \mathrm{chl} a \cdot \mathrm{h}^{-1}$ and $\alpha_{\mathrm{B}}$ values between $6.6-11.6 \mathrm{~g} \mathrm{C} \cdot \mathrm{m}^{2} \cdot \mathrm{mol}^{-1}$ quan$\mathrm{ta} \cdot \mathrm{g}^{-1} \operatorname{chl} a$. Hence, $\mathrm{P}_{\mathrm{B}}$ and $\alpha_{\mathrm{B}}$ vary 7.8 -fold and 1.7fold, respectively. We estimate $\theta$, being 3.5 -fold less under conditions of maximum growth relative to conditions when $\mu$ approaches 0 , to be in the range 3.2546.08 (Langdon 1988). The introduction of the carbon to chl $a$ ratio $\theta$ causes the maximum light-saturated growth rate to vary 108 -fold. 
Obviously, a better predictability of $\theta$ would be welcome. To address the question on predicting the value of $\theta$, and thereby also the behavior of growth dependent photo-adaptive processes, it is necessary to expand the model and replace the empirical value of $\gamma_{x}$ with metabolic and regulatory pathways, of which the required level of detail remains to be determined. A first step could be to replace the terminal rate of Fd reoxidation by a description in terms of its known four acceptor enzymes: FNR, FNiR, GOGAT, and FTR. A description of the activation of GOGAT would be of direct importance to the rate of chl synthesis, because glutamate is a key intermediate for pigment synthesis (Precali and Falkowski 1983). The redox states of the PQ-pool and/or the cytochrome b6/f complex are already explicitly given by the current model and could serve to describe light dependent gene expression or activation of enzymes.

If information on relevant enzymatic reactions (both equations and in vivo kinetic parameters) of the metabolism of an algal cell were available, it would in principle be possible to apply detailed modelling to interpret experimental data and predict the dynamic behavior of cells under changing environmental conditions and in the consequences of specific genetic changes. This straightforward type of modelling means translating the biochemistry into mathematics. The limitation of this kind of approach, however, is the lack of information on general regulatory and control aspects of metabolism, as well as the fact that complete data sets of good quality are more the exception than the rule. We suggest a solution of considering the dynamic behavior of the cell on the different levels of the time-scale hierarchy. The current model predicts the short-term responses of algal cells to changes in photon flux density. Moreover, the derived general degree of reduction $\left(\gamma_{x}\right)$ closes the gap between a bottom up description of photochemistry and phenomenological photosynthetic parameters like $\alpha$. Here, algal biomass synthesis is assumed to take place in the final steady state (described in terms of $\gamma_{x}$ ) that results from a physiological (longer than gene regulation) acclimation of the cells to a constant environmental condition. A future extension of the current model by taking into account the physiological acclimation of micro-algal cells subjected to well defined changes in environmental conditions will further enhance our understanding of phytoplankton behavior in a dynamic environment.

This work was funded by the German Research Foundation (DFG) and is part of the project TH 744/2-1.

Allen, J. F. 1995. Thylakoid protein phosphorylation, state 1-state 2 transitions, and photosystem stoichiometry adjustment: redox control at multiple levels of gene expression. Physiol. Plant. 93:196-205.

Baker, N. R. \& Webber, A. N. 1987. Interactions between photosystems. In Callow, J. A. [Ed.] Advances in Botanical Research. Academic Press, New York, pp. 2-66.
Bannister, T. T. 1979. Quantitative description of steady state, nutrient-saturated algal growth, including adaptation. Limnol. Oceanogr. 24:76-96.

Baumert, H. 1996. On the theory of photosynthesis and growth in phytoplankton. Part I: light limitation and constant temperature. Int. Rev. Gesamten Hydrobiol. 1:109-39.

Behrenfeld, M. J., Boss, E., Siegel, D. A. \& Shea, D. M. 2005. Carbon-based ocean productivity and phytoplankton physiology from space. Global Biogeochem. Cycles 19:GB1006, DOI: 10.1029/2004GB002299.

Bidigare, R.R, Ondrusek, M. E., Morrow, J. H. \& Kiefer, D. E. 1990. In vivo absorption properties of algal pigments. SPIE Vol. 1302. Ocean Opt. X:290-302.

Cramer, W. A. \& Knaff, D. B. 1989. Energy Transduction in Biological Membranes: A Textbook of Bioenergetics. Springer-Verlag, Berlin.

Crofts, A. R. \& Wraight, C. A. 1983. The electrochemical domain of photosynthesis. Biochim. Biophys. Acta 726:149-85.

Dubinsky, Z., Falkowski, P. G. \& Wyman, K. 1986. Light harvesting and utilization by phytoplankton. Plant Cell Physiol. 27: 1335-49.

Falkowski, P. G., Dubinsky, Z. \& Wyman, K. 1985. Growth-irradiance relationships in phytoplankton. Limnol. Oceanogr. 30: 311-21.

Flynn, K. J. 2003. Modelling multi-nutrient interactions in phytoplankton: balancing simplicity and realism. Prog. Oceanogr. $56: 249-79$.

Flynn, K. J., Fasham, M. J. R. \& Hipkin, C. R. 1997. Modelling the interactions between ammonium and nitrate uptake in marine phytoplankton. Philos. Trans. R. Soc. London B Biol. Sci. 352:1625-45.

Flynn, K. J. \& Hipkin, C. R. 1999. Interactions between iron, light, ammonium, and nitrate: insights from the construction of a dynamic model of algal physiology. J. Phycol. 35:1171-90.

Flynn, K. J., Marshall, H. \& Geider, R. J. 2001. A comparison of two N-irradiance interaction models of phytoplankton growth. Limnol. Oceanogr. 46:1794-802.

Gallegos, C. L. \& Platt, T. 1981. Photosynthesis measurements on natural populations of phytoplankton. In Platt, T. [Ed.] Physiological Bases of Phytoplankton Ecology. Can. Bull. Fish. Aquat. Sci. 210, pp. 103-12.

Geider, R. J. \& Platt, T. 1986. A mechanistic model of photoadaptation in microalgae. Mar. Ecol. Prog. Ser. 30:85-92.

Govindjee, 1995. Sixty-three years since Kautsky: chlorophyll a fluorescence. Aust. J. Plant Physiol. 22:131-60.

Harbinson, J. \& Baker, N. R. 1989. Relationship between the quantum efficiencies of photosystem I and II in pea leaves. Plant Physiol. 90:1029-34.

Hippler, M., Redding, K. \& Rochaix, J.-D. 1998. Chlamydomonas genetics, a tool for the study of bioenergetic pathways. Biochim. Biophys. Acta 1367:1-62.

Kiefer, D. A. \& Mitchell, G. B. 1983. A simple steady-state description of phytoplankton growth based on absorption cross-section and quantum efficiency. Limnol. Oceanogr. 21:664-72.

Kolber, Z. S., Prásil, O. \& Falkowski, P. G. 1998. Measurements of variable fluorescence using fast repetition rate techniques: defining methodology and experimental protocols. Biochim. Biophys. Acta 1367:88-106.

Kroon, B. M. A., Ketelaars, H. A. M., Fallowfield, H. J. \& Mur, L. R. 1989. Modelling microalgal productivity in a high rate algal pond based on wavelength dependent optical properties. $J$. Appl. Phycol. 1:247-56.

Langdon, C. 1987. On the causes of interspecific differences in the growth-irradiance relationship for phytoplankton. Part I. A comparative study of growth-irradiance relationship of three marine phytoplankton species: Skeletonema costatum, Olisthodiscus luteus and Gonyaulax tamarensis. J. Plankton Res. 9:459-82.

Langdon, C. 1988. On the causes of interspecific differences in the growth-irradiance relationship for phytoplankton. II. A general review. J. Plankton Res. 10:1291-312.

Lavergne, J. \& Trissl, H.-W. 1995. Theory of fluorescence induction in photosystem II: derivation of analytical expressions in a model including exciton-radical pair equilibrium and restrict- 
ed energy transfer between photosynthetic units. Biophys. J. 68:2474-92.

Lazár, D. 1999. Chlorophyll a fluorescence induction. Biochim. Biophys. Acta 1412:1-28.

Lebedeva, G. V., Belyaeva, N. E., Demin, O. V., Riznichenko, G. Yu. \& Rubin, A. B. 2002. Kinetic model of primary photosynthetic processes in chloroplasts. Description of the fast phase of chlorophyll fluorescence induction under different light intensities. Biophysics 47:968-80.

Marshall, H. L., Geider, R. J. \& Flynn, K. J. 2000. A mechanistic model of photoinhibition. New Phytol. 145:347-59.

Mills, J. D. 1996. The regulation of chloroplast ATP synthase, $\mathrm{CF}_{\mathrm{o}}-$ $\mathrm{CF}_{1}$. In Ort, D. R. \& Yocum, C. F. [Eds.], Oxygenic Photosynthesis: The Light Reactions. Kluwer Academic Publishers, Dordrecht, pp. $469-85$.

Morris, I. 1981. Photosynthetic products, physiological state, and phytoplankton growth. In Platt, T. [Ed.], Physiological Bases of Phytoplankton Ecology. Can. Bull. Fish. Aquat. Sci. 210, pp. 83-102.

Parsons, T. R., Takahashi, M. \& Hargrave, B. 1984. Biological oceanographic processes. 3rd ed. Butterworth-Heinemann Ltd, Oxford.

Precali, R. \& Falkowski, P. G. 1983. Incorporation of [14C]-glutamate into proteins and chlorophylls in Dunaliella tertiolecta, a marine chlorophyte. Biol. Plant. 25:187-95.

Robinson, H. H. \& Crofts, A. R. 1983. Kinetics of the oxidation-reduction reactions of the photosystem II quinone acceptor complex, and the pathway for deactivation. FEBS Lett. 153:221-6.

Roels, J. A. 1983. Energetics and Kinetics in Biotechnology. Elsevier Biomedical Press, Amsterdam, pp. 23-38.

Sakshaug, E., Johnsen, G., Andresen, K. \& Vernet, M. 1991. Modeling of light-dependent algal photosynthesis and growth: experiments with the Barents Sea diatoms Thalassiosira nordenskioldeii and Chaetoceros furcellatus. Deep Sea Res. A38: 415-30.
Schreiber, U., Schliwa, U. \& Bilger, W. 1986. Continuous recording of photochemical and non-photochemical chlorophyll fluorescence quenching with a new type of modulation fluorometer. Photosynth. Res. 10:51-62.

Schubert, H., Kroon, B. M. A. \& Matthijs, H. C. P. 1994. In vivo manipulation of the xanthophyll cycle and the role of zeaxanthin in the protection against photodamage in the green alga Chlorella pyrenoidosa. J. Biol. Chem. 269:7267-72.

Simpson, D. J. \& Knoetzel, J. 1996. Light-harvesting complexes in plants and algae. In Ort, D. R. \& Yocum, C. F. [Eds.], Oxygenic Photosynthesis: The Light Reactions. Kluwer Academic Publishers, Dordrecht, pp. 493-506.

Shuter, B. 1979. A model of physiological acclimation in unicellular algae. J. Theor. Biol. 78:519-52.

Stirbet, A., Govindjee, Strasser, B. J. \& Strasser, R. J. 1998. Chlorophyll a fluorescence induction in higher plants: modelling and numerical simulation. J. Theor. Biol. 193:131-51.

Sukenik, A., Bennet, J. \& Falkowski, P. G. 1987. Light-saturated photosynthesis-limitation by electron transport or carbon fixation? Biochim. Biophys. Acta 891:205-15.

Trissl, H.-W. \& Lavergne, J. 1994. Fluorescence induction from photosystem II: analytical equations for the yields of photochemistry and fluorescence derived from analysis of a model including exciton-radical pair equilibrium and restricted energy transfer between photosynthetic units. Aust. J. Plant Physiol. 22:183-93.

Trtilek, M., Kramer, D. M., Koblizek, M. \& Nedbal, L. 1997. Dualmodulation LED kinetic fluorometer. J. Lumin. 72-74:597-9.

Quigg, A., Beardall, J. \& Wydrzynski, T. 2003. Photoacclimation involves modulation of the photosynthetic oxygen-evolving reactions in Dunaliella tertiolecta and Phaeodactylum tricornutum. Funct. Plant Biol. 30:301-8.

Whitmarsh, J. \& Govindjee, 1995. Photosynthesis. Encycl. Appl. Phys. 13:513-32. 